\title{
Goal Cycle: Antecedents and Consequences of Goal Progress
}

\author{
Ewa Szumowska ${ }^{1 a}$, Katarzyna Jasko ${ }^{1 a}$, Karolina Dukała ${ }^{2}$, Paulina Górska ${ }^{3}$ \\ ${ }^{1}$ Jagiellonian University, Department of Philosophy, Institute of Psychology \\ ${ }^{2}$ SWPS University of Social Sciences and Humanities \\ ${ }^{3}$ University of Warsaw, Faculty of Psychology \\ ${ }^{a}$ Shared first authorship
}

\begin{abstract}
Author Note
Ewa Szumowska (D) https://orcid.org/0000-0002-4181-6175

Katarzyna Jaśko (D https://orcid.org/0000-0002-3195-8268

Karolina Dukała iD https://orcid.org/0000-0001-9564-3102

Paulina Górska (iD https://orcid.org/0000-0002-2433-4588
\end{abstract}

The Authors declare no conflict of interest.

Correspondence concerning this article should be addressed to Ewa Szumowska, Institute of Psychology, Jagiellonian University, Ingardena Str. 6, 30-060 Krakow, Poland. Email: ewa.szumowska@uj.edu.pl

\section{Acknowledgements}

This research was supported by a grant from the National Science Center (2015/19/B/HS6/01253) awarded to Katarzyna Jaśko. 


\title{
Goal Cycle: Antecedents and Consequences of Goal Progress
}

\begin{abstract}
Even though goal pursuit is often conceptualized as a linear phenomenon, it consists of feedback loops and reciprocal relationships between its crucial components. To investigate this cyclical aspect, we tested the relationships between core goal properties (i.e., goal importance and expectancy of success) as well as goal-related emotions (satisfaction and stress) and goal progress over time. In longitudinal Study $1(N=390)$, across three waves and 3,156 unique goals, we found that progress on personal goals was not only positively predicted by expectancy and, less consistently, by goal importance, but also by goal-related satisfaction and, to a lesser extent, stress. Moreover, goal progress positively predicted future progress through increased importance, increased expectancy, and increased satisfaction and negatively through decreased stress, indicating an overall self-reinforcing feedback loop. In Study $2(N=235)$, we experimentally manipulated subjective progress on the weekly goal of walking and observed its positive effects on goal importance, expectancy, and satisfaction, but not stress. Once again, we demonstrated a positive indirect effect of (manipulated) goal progress on subsequent progress via increased satisfaction. These results provide insight into the mechanisms of goal-pursuit viewed as a cyclic process.
\end{abstract}

Keywords: goal progress, goal importance, expectancy, satisfaction, stress, goal cycle 


\section{Introduction}

The question of what determines successful goal pursuit has engaged both scientists and lay people for a long time. Starting from classical theories of motivation (e.g., Hull, 1932) to more contemporary views (e.g., Kruglanski et al., 2014), researchers have tried to identify goal properties that make people more likely to attain what they desire. Numerous studies have shown the importance of the goal and the expectancy of its success as main predictors of effort invested in the goal and ultimately progress on the goal (e.g., Atkinson \& Birch, 1970; Lewin et al., 1994; Kruglanski et al., 2014). Fewer studies, however, have investigated the other side of this relationship, namely how goal progress affects further motivation, and thus potentially impacts future progress (cf. Hull, 1932, 1934; Vancouver et al., 2010). Moreover, whereas it has been demonstrated that goal progress (or lack thereof) is directly related to emotional reactions such as feelings of satisfaction or frustration, the effects of these emotional states on subsequent progress have been studied much less often. As a result, it remains unclear how positive emotions brought about by progress or negative emotions resulting from the lack of it impact subsequent progress.

In short, whereas past research has typically considered importance and expectancy as antecedents of goal progress and satisfaction and frustration as its consequences, we propose that all these characteristics can be treated as both antecedents and consequences that affect and are affected by goal progress. In the present research, we propose and test a full goal cycle that includes all these relations. First, in longitudinal Study 1, we examine these relations in the context of personal goals over the course of several months. In Study 2, we experimentally manipulate goal progress to test causal directions between these variables. In the sections that follow, we present a short overview of the literature pertaining to the components of the goal 
GOAL CYCLE

cycle, identify inconsistencies in this literature, and outline competing hypotheses that inspired our research.

\section{Goal Importance, Expectancy, and Goal Progress}

According to both classical (e.g., Atkinson \& Birch, 1970; Lewin et al., 1994; Vroom, 1964) and more recent (Kruglanski et al., 2014) theories of human motivation, individuals are motivated to pursue goals they find important and attainable. Thus, the two primary determinants of motivation toward a given goal are its importance (i.e., subjective value) and subjective expectancy of success in achieving it. If they are both above the threshold level, commitment to the goal is formed and it gets sent forth to an implementation phase (e.g., Gollwitzer \& Bayer, 1989; Kruglanski et al., 2014). The same properties responsible for setting goals also matter for pursuing those goals and, ultimately, in progressing toward the goals. Research shows that the more important a given goal is, the more motivated an individual is to invest effort in it, which in turn translates into better performance and greater chances of success (e.g., Kruglanski et al., 2012; Wright, 2008; Hollenbeck \& Williams, 1987; Nurmi et al., 2002). For instance, King, Richards, and Stemmerich (1998) found a positive relationship between goal importance and daily goal progress. Other research has shown that individuals engage in task-relevant behaviors when the task is perceived to be important (e.g., Ingledew et al., 2005; Szumowska et al., 2018; Yukl et al., 1999), even if those behaviors are costly or extreme (Kruglanski et al., 2022).

Expectation of success is similarly related to greater goal progress. Ample evidence suggests that positive outcome expectancies lead individuals to initiate and maintain commitment to a goal (Carver \& Scheier, 1988; Kruglanski et al., 2014) and increase persistence and effort invested in the task necessary to reach the goal (Zhang \& Fishbach, 2010). For instance, studies on domain-specific self-efficacy demonstrated the power of beliefs that one can 
perform the behavior that serves an important goal. Their motivating role has been shown in various domains such as work and achievement goals (e.g., Vroom, 1964), health goals (e.g., Affleck et al., 2001), learning and academic goals (e.g., Wigfield \& Eccles, 2000), and helping goals (Kossowska et al., 2020). In contrast, people who have negative expectancies about future are more likely to disengage from a goal, and more likely to fail as a consequence (Carver \& Scheier, 2014). Taken together, the above evidence shows that the greater the importance and expectancy assigned to a goal, the higher the resulting motivation should be and, consequently, greater progress is made toward the goal. What is less clear, however, is how progress on a given goal subsequently affects the importance and expectancy.

Classic findings would suggest that the greater the past progress, the greater the motivation to attain the goal should be. According to the so-called goal gradient hypothesis, originally formulated by Hull $(1932,1934)$, the tendency to approach a goal increases with proximity to the goal. Indeed, research shows that people working toward future rewards accelerate their effort as they near the reward goal (e.g., Cryder, Loewenstein, \& Seltman, 2013; Kivetz, Urminsky, \& Zheng, 2006; Liberman \& Forster, 2012). This mainly happens because they view the goal as more attainable, which in turn gives them a heightened sense of personal impact and satisfaction and motivates action (e.g., Forster, Higgins, \& Idson, 1998; Liberman \& Forster, 2012). A similar dynamic notion of increased expectancy is expressed in more recent computational models of goal pursuit (Vancouver et al., 2010), which suggest that progress increases motivation by reducing the discrepancy between the current and the desired state, thus increasing expectancy.

A similar pattern could be argued for goal importance. If progress is interpreted as a sign that one really cares about the goal, then the importance attached to the goal should increase as 
GOAL CYCLE

one gets closer to the goal. Studies demonstrated that when positive feedback informs a person about their engagement in the goal, the consistent behavior toward the same goal is more likely to follow (Fishbach et al., 2006, 2010; Ryan \& Deci, 2000). Studies have also shown that the value of an outcome is discounted or diminished as temporal distance from the outcomes increases, i.e., individuals often place higher value on a near future reward than on a distant future reward, even when the distant future reward is larger (e.g., Mischel, 1974; Read, Loewenstein, \& Kalyanaraman, 1999). This suggests that progress (and goal proximity) should positively affect goal importance.

Other motivational theories, however, make exactly the opposite prediction, suggesting that progress on a goal should decrease the importance assigned to that goal. Instead of increasing subsequent effort it would rather lead to temporary disengagement from it and switching to a different one. One such model is control theory (Carver \& Scheier, 1998), according to which people are motivated by discrepancies between the actual and desired end states. Since the lack of progress induces greater discrepancy, it should also increase subsequent goal commitment because such a situation suggests that more effort is needed (Carver \& Scheier, 1998; Higgins, 1987; Miller, Galanter, \& Pribram, 1960; Powers, 1973). In contrast, goal progress reduces the discrepancy and provides a sense of partial goal attainment. This means that less effort is needed, and a person can turn to their other concerns (see also Fishbach et al., 2006, 2010; Fishbach \& Dhar, 2005; Vancouver et al., 2010). This prediction is however contrary to what could be expected based on the goal gradient hypothesis, thus suggesting that two competing hypotheses about the effect of goal progress on importance can be made.

In short, on the basis of the theoretical arguments presented above, both goal importance and expectancy should positively predict goal progress. Goal progress should also positively 
GOAL CYCLE

predict subsequent expectancy. Therefore, there should be a positive indirect effect of goal progress on further progress via expectancy. However, when it comes to the consequences of goal progress for goal importance two alternative predictions can be formed. On the one hand, if goal progress signals enhanced commitment, it should increase the importance of the goal. On the other hand, by decreasing the discrepancy between the desired versus current state, goal progress could lower current goal importance. The first goal of the present research is to test these competing hypotheses directly and address the relationship between goal importance, expectancy, and progress over time.

\section{Goal-Related Emotions and Goal Progress}

Our second question focused on the reciprocal relationship between emotions and goal progress. Generally, emotional states inform people about where they stand in relation to their goals (e.g., Carver, 2004; Carver \& Scheier, 2009; Oatley \& Johnson-Laird, 1987; Stein, Liwag, \& Wade, 1996). Put simply, people are satisfied when they make progress toward their goals, and they feel stressed and frustrated when the progress is slow or non-existent. This result is consistent with research showing that goal progress is connected to well-being and lack of progress is connected to stress (Maier \& Brunstein, 2001; Sheldon et al., 2002). For example, Krys, Otte and Knipfer (2020) showed in a longitudinal study that lack of progress leads to psychological distress. The same pattern of results can be found for personal goals such as workrelated goals (Wiese \&Freund, 2005) or weight control goals (Bagozzi et al., 1998). However, whereas emotional reactions to goal progress (or lack of it) are rather straightforward, their consequences for subsequent progress are less certain.

On the one hand, in line with the control theory mentioned earlier (Carver \& Scheier, 1998, 2009), when people experience frustrations with regard to their goals, it may indicate that 
GOAL CYCLE

the task is more difficult than expected and they should adjust their efforts to match the difficulty level. In other words, if feeling stressed informs people that they are far away from their desired end states, they should increase their investment in that goal (Carver \& Scheier, 1998).

Experiencing stress would facilitate mobilization of the necessary resources to deal with more challenging tasks and would lead to a higher performance level. In contrast, satisfaction indicates that an individual is getting closer to achieving their goals. It signals that enough progress has been made and one can, at least temporarily, turn their attention to other goals. Indeed, there are some studies demonstrating the motivating function of negative emotions for goal progress (e.g., anger, Lench \& Levine 2008).

However, the opposite theoretical view suggests that it is the satisfaction with progress and positive emotions gained from the pursuit of the goal that should increase subsequent engagement. According to this logic, positive feelings indicate both high value and high expectancy of the goal whereas negative feelings suggest that the goal might be out of reach. If that is true then satisfaction with goal progress would boost self-efficacy, motivate goal commitment, and increase effort invested in the goal (Bandura, 1977). Another reason why positive emotion may intensify goal pursuit is through inducing intrinsic motivation (Deci \& Ryan, 1991). When people gain a sense of control and competence from pursuing the goal, they are more likely to develop a positive attitude toward it and be more willing to invest in it in the future. Indeed, research conducted in various domains showed that when people experience positive affect while pursuing their goal, they are more committed to the goal and more motivated to pursue it further (Lawton et al., 2009; Woolley \& Fishbach, 2017).

Given these inconsistencies, in the current research, we examine how the progress one has made toward their goal(s) affects subsequent progress toward the goal(s) and what role goal- 
GOAL CYCLE

related emotions play in the process. Specifically, in line with past studies, we predict that progress positively affects satisfaction and negatively affects stress. Extending past research, we test how these feelings mediate the path to further progress. On the one hand, past progress could facilitate further progress if increased satisfaction and decreased stress are primary motivators. However, if people are more predominantly motivated by the negative feelings evoked by frustration and lack of progress, then the path from past to future progress should be negative.

\section{Present Research}

To test our hypotheses, we ran two studies. In Study 1 we utilized a longitudinal design and monitored personal goals of students over the course of one semester. At three time points, we measured importance and expectancy attached to these goals, emotions they evoked, and subjective progress. To address the issue of causality, we ran Study 2 in the form of a weekly walking challenge, in which we manipulated the sense of goal progress. We tested the effects of this manipulation on goal importance, expectancy, and goal-related emotions, as well as its indirect effects on future (objective and subjective) progress. In short, by examining how goal importance, expectancy, and emotions change with progress and how these changes, in turn, bring about future progress, we intended to document a full goal cycle (see Figure 1).

\section{Figure 1}

Goal Cycle: Conceptual Model Tested in the Current Studies 


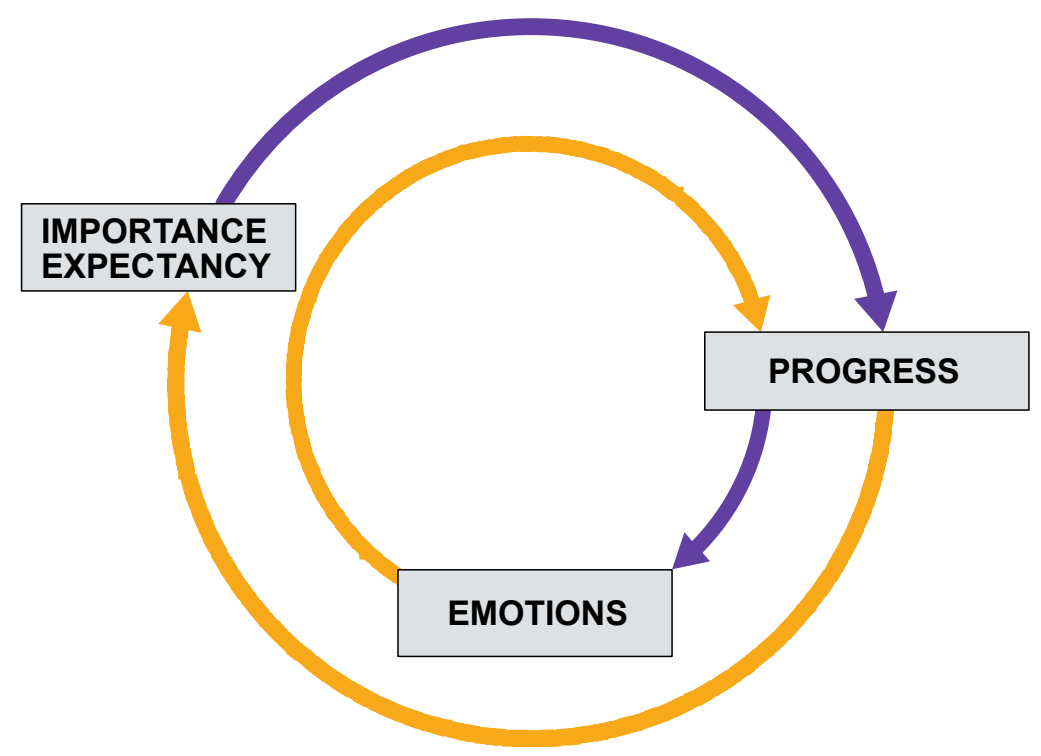

Note. We mark paths that were typically studied in previous research in purple. We mark less documented paths in orange.

\section{Study 1}

To test the relationships between goal importance and expectancy, goal progress, and goal-related emotions, we ran a longitudinal study in which the same participants were tested three times over the course of one semester. Participants were students recruited at the beginning of a semester. They indicated their goals for the upcoming semester and rated several features of each of these goals (i.e., importance, expectancy, progress, satisfaction, and stress). The same goal characteristics were measured after two months (Wave 2) and after another two months (Wave 3). The third data collection was scheduled immediately after the semester had ended.

First, we predicted that the importance and expectancy attached to a given goal would positively predict progress on that goal reported at the following wave. Furthermore, we 


\section{GOAL CYCLE}

predicted perception of the goal's progress to be related positively to the following goal characteristics: expectancy and goal importance (commitment hypothesis). Taken together, we expected goal progress at a given time point to predict goal progress at a subsequent time point via two positive paths: increased expectancy and increased goal importance. Alternatively, according to the discrepancy hypothesis, greater goal progress would decrease the importance of a goal and lead to goal disengagement and lower goal progress at a subsequent time point.

Second, we hypothesized that goal progress would have affective consequences, such that perception of greater past progress would be related to greater satisfaction and lower stress measured at the same time point (Carver \& Scheier, 2009; Simon, 1967). These emotions would in turn predict future progress. The direction of the influence, however, was less straightforward. Based on the discrepancy hypothesis, higher satisfaction should lead to lesser progress in the future but stress should lead to more progress in the future. However, based on the commitment hypothesis, satisfaction should motivate further progress whereas feelings of stress should lead to disengagement. Hence, current progress can affect future progress via two emotional paths (satisfaction and stress), but the direction depends on the theoretical model. Some of these hypotheses were preregistered (in most cases, however, we had to diverge from the preregistration protocol, see Supplementary Material A for preregistration status of each hypothesis). All study data, materials and scripts are publicly available via osf.io. We report how we determined our sample size, all data exclusions (if any), all manipulations, and all measures in the study.

\section{Method}


GOAL CYCLE

\section{Participants}

Only students took part in the study. They were recruited via announcements on local social media portals and via the university recruitment system. They were invited to take part in a three-wave online survey. Monetary compensation was offered: 10 PLN $(\sim \$ 3)$ for participation in the first wave, 20 PLN $(\sim 6)$ for participation in the second wave, and 30 PLN $(\sim 9 \$)$ for participation in the third wave.

Three-hundred and ninety (390) students of various majors took part in the first wave. There were 314 women, 74 men, and 2 participants who indicated 'other' as gender. Participants' ages ranged from 18 to 44 years $(M=22.19, S D=2.65)$. Out of these participants, $350(89.74 \%)$ took part in the second wave and $311(79.74 \%)$ in the third wave. This meets our minimum expected sample size (see preregistration protocol). The study was conducted in accordance with the guidelines of the local Research Ethics Committee and with informed consent from all participants.

\section{Materials and Procedure}

The data was collected in three waves over the course of one semester. The first wave of data collection occurred two weeks after the start of the Fall semester. The second wave of data collection was during the mid-term period, and the third wave was after the end of the semester. Only participants who had completed the first survey were invited to the second one; likewise, only those who had completed the second survey were invited to the third one. Participants' personal goals were measured in each of the three waves (in total, participants named 3,158 unique goals). Below we describe each of the surveys in detail.

\section{Wave 1}


GOAL CYCLE

After providing informed consent, participants were asked a set of demographic questions and were then asked to indicate the goals they were planning to pursue during the upcoming semester. Particularly, they were presented with the following instructions:

People have different goals in their lives. The goals can be general (e.g., be happy in life, have a satisfying social life) or more specific (e.g., learn how to write calligraphy, run a marathon, or get an A on a chemistry exam). We are interested in how you perceive your goals. Indicate ALL goals that you are planning to pursue IN THIS SEMESTER. It is important to us that you name the goals which you are planning to pursue in this semester but not necessarily have to attain them in this time period. You can also name goals you have already initiated.

Participants could name up to ten goals (the maximum number of goals was determined based on the results of a pilot study, which showed that participants named six goals on average). In the first wave, participants indicated 2,804 goals in total. Then, participants were asked a set of questions about each of the goals they named ${ }^{1}$.

\section{Wave 2}

In the second survey, participants were presented with the same goals they had indicated in the first wave. Then, in reference to each goal, participants were asked to select one of two options: 1) "This goal is still my goal” or 2) "This goal is no longer my goal." They were also asked whether they had started any new goals since the last survey; if so, they were asked to name them (up to five new goals). They indicated 2,878 goals in total. While 352 of these goals were not included in Wave 1, 397 of old goals were reported as "no longer a goal". Next, they were asked the same questions as in Wave 1 about each of the active goals they listed.

\footnotetext{
${ }^{1}$ At the end of survey, participants were also asked to fill in a set of individual difference measures. These, however, pertain to a different research question and are thus not presented here.
} 
GOAL CYCLE

\section{Wave 3}

In the final survey, participants were presented with all their goals (all goals they had named in the previous waves). Then, they were asked whether each of the goals was still their goal. We modified the question from Wave 2 and participants could answer by choosing one of the three options: 1) "Yes, this goal is still my goal;" 2) "No, I quit before attaining the goal;" or 3) "The goal was successfully attained." This way, we could differentiate between the instances when the goal has been dropped vs. attained. There were 2,541 goals in total: 310 were goals added in Wave 2. Out of all the goals included in this wave, 601 were reported as successfully attained.

In reference to non-quit goals (option 1 or 3 selected), participants were asked the same set of questions about each goal as in previous waves. However, questions about goal expectancy and goal progress were supplemented with an additional option indicating "The goal has already been attained." If this option was selected, a given (attained) goal was assigned a 7 (maximum score) on progress and expectancy.

At the end of the survey, participants were debriefed and thanked for their participation in the whole study.

\section{Measures}

Goal importance. The importance of each goal was measured with two items: 1) How important is this goal to you? (1 - Not at all important to 7 - Very important) and 2) How important is this goal to you relative to other goals? (1 - The least important of my goals to 7 The most important of my goals). A score of importance was computed by averaging responses to the two items. The correlation between the two items was equal to $r_{\mathrm{T} 1}=.84, p<.001 ; r_{\mathrm{T} 2}=$ $.85, p<.001$, and $r_{\mathrm{T} 3}=.85, p<.001$. 
GOAL CYCLE

Goal expectancy. The expectancy of goal attainment was measured with one item: Rate the likelihood of you attaining the goal (1 - Unlikely to 7 - Very likely).

Goal progress. Goal progress was measured with one item: Rate the progress you have made on this goal until now (1 - I have not started yet to 7 - The goal is close to being completed).

Goal-related satisfaction. Participants' satisfaction was measured with the item: To what extent are you satisfied with the progress on this goal until now? (1 - Very unsatisfied to 7 Very satisfied).

Goal-related stress. We also asked participants to evaluate the level of stress related to each of their goals: To what extent does thinking about this goal stress you out? (1 - It does not stress me out at all to 7 - It stresses me out a lot).

All questions ${ }^{2}$ were presented in a fixed order, but the goal order was randomized.

\section{Analytical Strategy}

First, we checked what amount of variance could be attributed to the individual and the goal levels of analysis. To this end, we estimated five null models in which importance, expectancy, progress, satisfaction, and stress served as dependent variables, respectively. In all of these models, measurements (level-1 units) were nested in goals (level-2 units), and goals were nested in individuals (level-3 units). We also estimated 15 null models specifying importance, expectancy, progress, satisfaction, and stress assessed across consecutive measurements as dependent variables. All of these models had a two-level structure with goals (level-1 units) nested in individuals (level-2 units).

\footnotetext{
${ }^{2}$ For exploratory purposes, we measured a few additional variables. Since they are not relevant to the present research question (and not included in the pre-registration), we present them in Supplementary Materials C.
} 
GOAL CYCLE

To test our hypotheses, we employed a multilevel structural equation modeling (MSEM) framework (Preacher, Zyphur, \& Zhang, 2010), which allows partitioning level-1 and level-2 latent components of observed level-1 variables. In the present case, importance, expectancy, progress, satisfaction, and stress assessed at consecutive waves of our study served as the 15 observed goal-level (level-1) variables. The relationships between the latent components of observed variables were identical at the goal and the individual-level (level-2) of analysis (see Figure 2A for the goal-level and Figure 2B for the individual-level). Similar to the pattern known from autoregressive cross-lagged panel models, each T2 latent variable was regressed on all T1 latent variables, and each T3 latent variable was regressed on all T2 latent variables. At the same time, within each wave of our study, goal importance, goal expectancy, goal satisfaction, and goal stress were regressed on goal progress. Finally, to obtain $95 \%$ confidence intervals for the 1-1-1 indirect effects, we employed parametric bootstrapping with 20,000 re-samples. ${ }^{3}$ Missing data $(20.43 \%)$ was handled with full information maximum likelihood estimation which uses all available data to produce estimates. ${ }^{4}$ All models were performed in Mplus 8.1 and relied on MLF estimator (Muthén \& Muthén, 2018). All participants who completed at least one wave were included in the analyses. The results for the restricted sample of participants who completed all three waves are presented in Supplementary Materials B.

\section{Results}

\section{Intraclass Correlations}

Table 1 shows individual- and goal-level ICCs for our focal variables. As shown, variability in participants' responses was greater at the level of goals than individuals. Similar

\footnotetext{
3 95\% CIs were estimated with the online utility provided by Selig and Preacher (2008).

${ }^{4}$ Handling missing data with multiple imputation did not change the substantive conclusions (see Supplementary Material B).
} 
GOAL CYCLE

results were obtained for the 15 null models in which goals were nested within individuals (Table S5, Supplementary Material B). The amount of variance accounted for by the individual level of analysis ranged from 3.2\% for goal importance assessed at T1 to $15.9 \%$ for goal stress assessed at T3. Taken together, participants' responses showed much greater variability at the goal rather than the individual level of analysis.

\section{Table 1}

Intraclass Correlation Coefficients at the Individual and the Goal Level of Analysis (3-Level Data Structure)

\begin{tabular}{llll}
\hline & ICClevel 3 & ICC $_{\text {level } 2}$ & $\chi^{2}(1)$ \\
\hline Goal importance & $.043 * * *$ & $.650 * * *$ & $472.59 * * *$ \\
Goal expectancy & $.099 * * *$ & $.394 * * *$ & $110.90 * * *$ \\
Goal progress & $.080 * * *$ & $.267 * * *$ & $60.14 * * *$ \\
Goal satisfaction & $.101 * * *$ & $.312 * * *$ & $64.45 * * *$ \\
Goal stress & $.112 * * *$ & $.506 * * *$ & $177.42 * * *$ \\
\hline Note. Level 3 $=$ individual level of analysis. Level $2=$ goal level of analysis. & \\
&
\end{tabular}

Next, we tested a full MSEM model, in which each variable assessed at T2 and T3 was regressed on all variables measured at $\mathrm{T} 1$ and $\mathrm{T} 2$, respectively, and goal progress was allowed to predict the remaining variables assessed within a given measurement occasion (Figures $2 \mathrm{~A}$ and 
2B). The fit of this model was satisfactory, $\chi^{2}(50)=374.84, \mathrm{CFI}=.984, \mathrm{RMSEA}=.045$,

$\mathrm{SRMR}_{\text {within }}=.026, \mathrm{SRMR}_{\text {between }}=.033^{5}$. Figure $2 \mathrm{~A}$ presents the results obtained for the goal level of analysis.

\section{Goal Importance, Expectancy and Goal Progress}

First, we checked whether goal importance and goal expectancy exerted longitudinal effects on goal progress. In line with expectations, goal progress assessed at T2 was predicted positively by goal importance $(B=0.11, S E=0.04,95 \% C I[0.03,0.20], p=.006)$ and goal expectancy $(B=0.12, S E=0.05,95 \% C I[0.03,0.21], p=.008)$ measured at T1. However, goal progress assessed at T3 was predicted positively by goal expectancy $(B=0.26, S E=0.05,95 \%$ $C I[0.17,0.36], p<.001)$ but not by goal importance $(B=0.08, S E=0.05,95 \% C I[-0.02,0.18]$, $p=.102)$ assessed at $\mathrm{T} 2$.

Further, we hypothesized that goal progress would serve as a positive predictor of goal expectancy assessed in the same measurement occasion. In line with this theorizing, goal progress predicted goal expectancy positively at T1 $(B=0.34, S E=0.03,95 \% C I[0.29,0.40], p$ $<.001), \mathrm{T} 2(B=0.37, S E=0.03,95 \% C I[0.31,0.43], p<.001)$ and T3 $(B=0.48, S E=0.02$, $95 \% C I[0.44,0.53], p<.001)$.

With regard to the relationship between perceived goal progress and goal importance, we theorized that goal progress could be a positive (i.e., commitment hypothesis) or a negative (i.e., discrepancy hypothesis) predictor of goal importance measured in a given measurement occasion. As presented in Figure 2A, goal progress was a positive predictor of goal importance at $\mathrm{T} 1(B=0.20, S E=0.03,95 \% C I[0.15,0.24], p<.001)$, at $\mathrm{T} 2(B=0.14, S E=0.03,95 \% C I$

\footnotetext{
${ }^{5}$ Importantly, the nonstationary model presented in Figures $2 \mathrm{~A}$ and $2 \mathrm{~B}$ fitted data better than the stationary model that imposed equality constraints on the corresponding paths assessed within and between the measurement occasions, $\chi^{2}(116)=675.71, p<.001, \mathrm{CFI}=.973, \mathrm{RMSEA}=.039, \mathrm{SRMR}_{\text {within }}=.044, \mathrm{SRMR}_{\text {between }}=.072, \Delta \chi^{2}(66)=$ $300.87, p<.001$. Therefore, we employed the nonstationary model estimates to verify our predictions.
} 
GOAL CYCLE

$[0.09,0.19], p<.001)$, and at T3 $(B=0.07, S E=0.02,95 \% C I[0.02,0.11], p=.003)$. Thus, the current results support the commitment rather than discrepancy hypothesis.

Next, we hypothesized that goal progress at a given time point would predict subsequent goal progress via two paths: positively via expectancy and positively or negatively via goal importance. In line with these expectations, the indirect effect of goal progress at T1 on goal progress at T2 via goal expectancy $(I E=0.04, S E=0.02,95 \% C I[0.01,0.07], Z=2.62, p=$ $.009)$ and goal importance $(I E=0.02, S E=0.01,95 \% C I[0.01,0.04], Z=2.64, p=.008)$ assessed at T1 was significant. At the same time, the effect of goal progress measured at T2 on itself at T3 was mediated by T2 goal expectancy $(I E=0.10, S E=0.02,95 \% C I[0.06,0.14], Z=$ $5.14, p<.001)$ but not by T2 goal importance, $(I E=0.01, S E=0.01,95 \% C I[-0.002,0.03], Z=$ $1.58, p=.113)$

\section{Goal Progress and Goal-Related Emotions}

We also hypothesized that, within a given measurement occasion, goal progress would predict greater goal satisfaction and lower goal stress. In line with these expectations, goal progress served as a positive predictor of goal satisfaction at $\mathrm{T} 1(B=0.61, S E=0.02,95 \% C I$ $[0.57,0.66], p<.001), \mathrm{T} 2(B=0.66, S E=0.02,95 \% C I[0.64,0.74], p<.001)$, and T3 $(B=$ $0.77, S E=0.03,95 \% C I[0.72,0.82], p<.001)$. Likewise, the effect of goal progress on goal stress was negative at T1 $(B=-0.07, S E=0.03,95 \% C I[-0.18,-0.06], p=.032), \mathrm{T} 2(B=-0.11$, $S E=0.03,95 \% C I[-0.18,-0.06], p=.001)$, and at T3 $(B=-0.10, S E=0.03,95 \% C I[-0.19,-$ 0.05], $p=.001)$.

Next, we tested whether goal satisfaction and goal stress would have effects on subsequent goal progress. The present data offered partial support to this theorizing. Specifically, while goal satisfaction $(B=0.21, S E=0.06,95 \% C I[0.09,0.33], p=.001)$ and goal stress $(B=0.15, S E=$ 
GOAL CYCLE

$0.04,95 \% C I[0.08,0.23], p=.001)$ assessed at $\mathrm{T} 2$ both had positive effects on goal progress at T3, goal progress measured at T2 was predicted by goal satisfaction at T1 $(B=0.11, S E=0.05$, $95 \% C I[0.02,0.20], p=.018)$ but not by goal stress at T1 $(B=-0.02, S E=0.04,95 \% C I[-0.08$, $0.05], p=.662)$.

Finally, we tested whether the effect of goal progress on itself in the next measurement occasion would be mediated by goal satisfaction and goal stress. Indeed, goal progress at T1 predicted goal progress at $\mathrm{T} 2$ by increased goal satisfaction at $\mathrm{T} 1(I E=0.07, S E=0.03,95 \% C I$ $[0.01,0.12], Z=2.35, p=.019)$, and goal progress at T2 predicted goal progress at T3 by increased goal satisfaction at $\mathrm{T} 2, I E=0.14, S E=0.04,95 \% C I[0.06,0.22], Z=3.40, p=.001$. At the same time, while the negative effect of goal progress assessed at $\mathrm{T} 2$ on goal progress at $\mathrm{T} 3$ was mediated by decreased goal stress at $\mathrm{T} 2(I E=-0.02, S E=0.01,95 \% C I[-0.03,-0.01], Z$ $=-2.64, p=.008$ ), goal stress at $\mathrm{T} 1 \mathrm{did}$ not mediate the indirect effect of goal progress at $\mathrm{T} 1 \mathrm{on}$ itself at T2, $I E=0.001, S E=0.002,95 \% C I[-0.004,0.01], Z=0.43, p=.666$. 


\section{Figure 2A}

Study Results for the Goal-Level

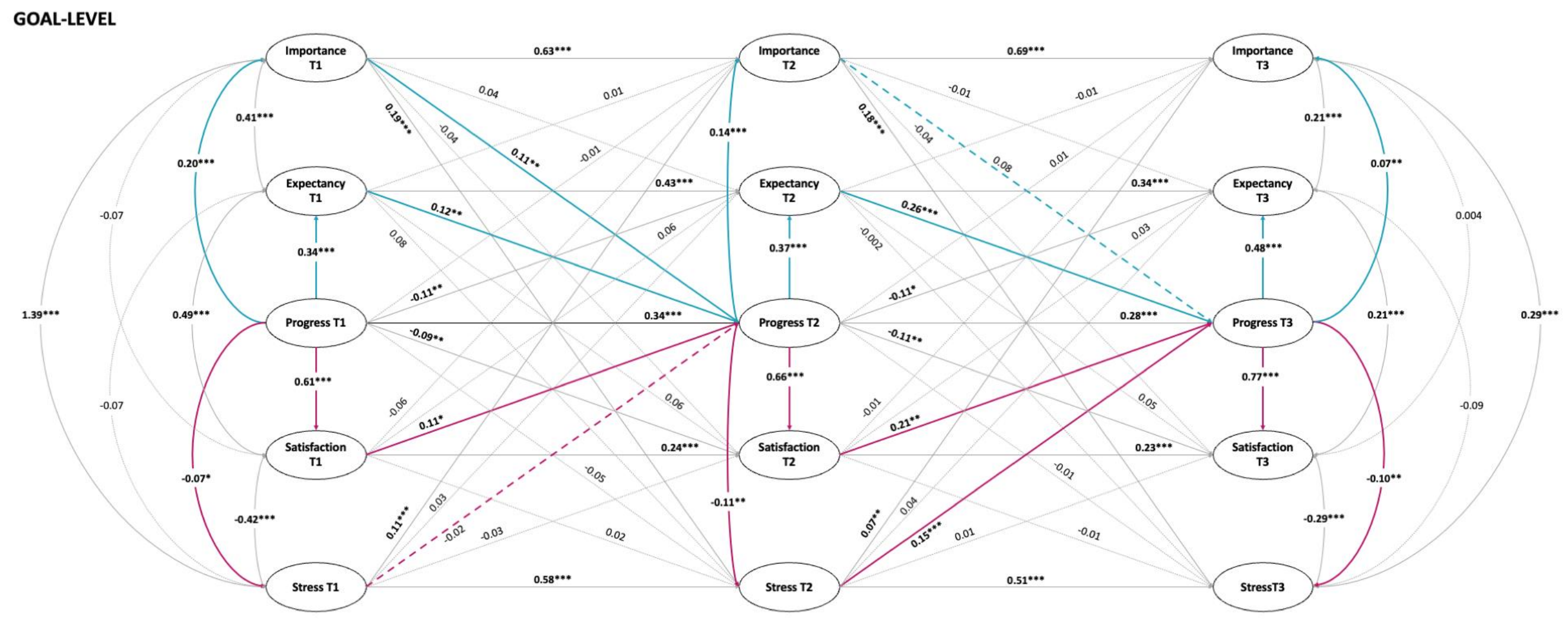

Note. Entries are unstandardized estimates. Hypothesized paths are presented in color. Paths from importance and expectancy to progress and vice versa are marked in blue, and from progress to emotions and from emotions to progress in purple. Solid and dashed lines represent significant and nonsignificant effects, respectively. For the sake of readability, covariances between importance, expectancy, satisfaction, and stress at T2 are not presented. $* p<.05 * * p<.01 * * * p<.001$ 


\section{Figure 2B}

Study Results For The Person-Level

\section{PERSON-LEVEL}

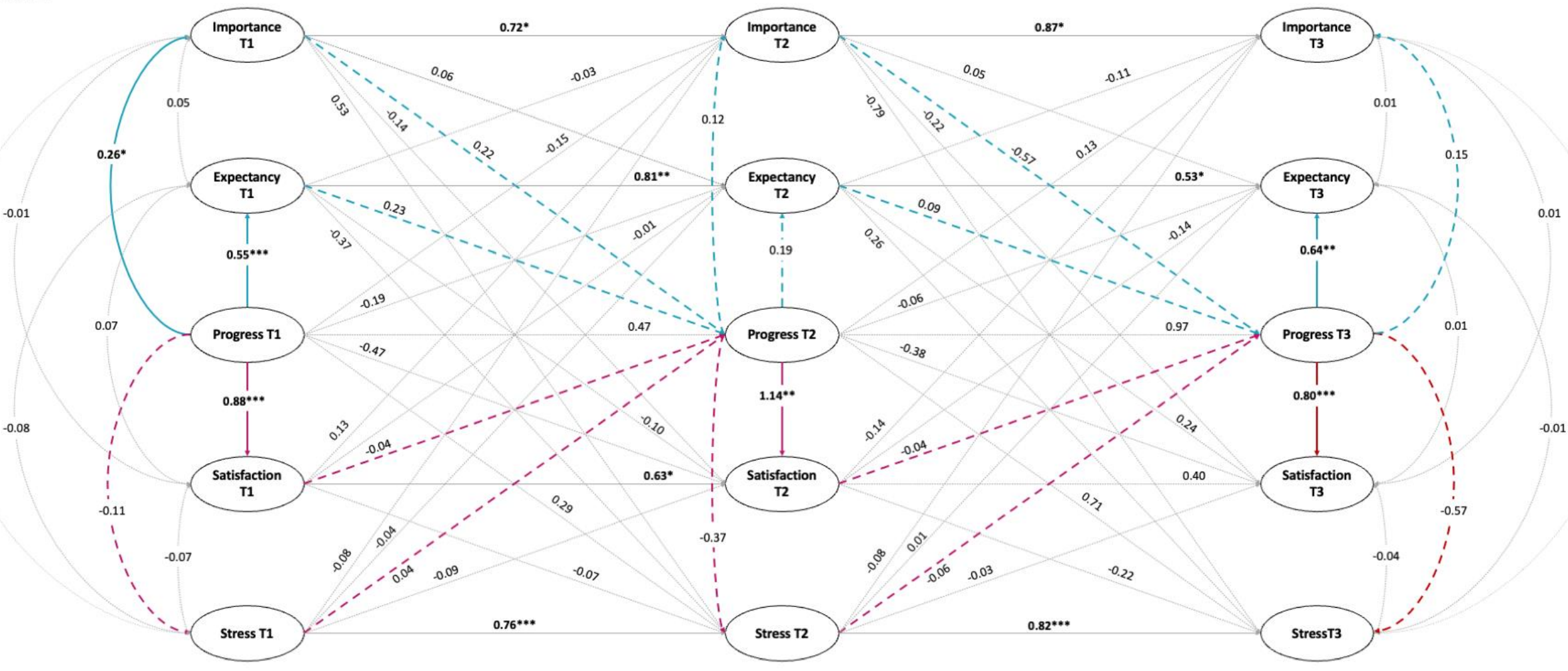

Note. Entries are unstandardized estimates. Hypothesized paths are presented in color. Paths from importance and expectancy to progress and vice versa are marked in blue, and from progress to emotions and from emotions to progress in purple. Solid and dashed lines represent significant and nonsignificant effects, respectively. For the sake of readability, covariances between importance, expectancy, satisfaction, and stress at T2 are not presented.

$* p<.05 * * p<.01 * * * p<.001$ 


\section{Discussion}

The goal of Study 1 was to examine the reciprocal relationships between importance, expectancy, and goal-related emotions on the one hand and goal pursuit on the other hand. Of two alternative hypotheses regarding the temporal dynamic between these factors, namely the commitment hypothesis and the discrepancy hypothesis, the results provided more consistent support for the former rather than the latter. Specifically, whereas goal progress was positively (rather than negatively) related to goal importance and satisfaction was a positive predictor of goal progress measured after two months, the positive effect of stress was observed only between the second and third wave. These findings suggest that progress (and resulting satisfaction) induces greater subsequent commitment. In contrast, we did not find support for the notion that progress decreases motivation via reduced distance to the goal.

However, given that we measured the relationships between goal progress and the other four variables simultaneously within the same wave, the causality of those paths remains unclear. For instance, it is plausible that participants were motivated to perceive larger progress on their important (vs. less important) goals, which could account for the correlation between these two variables. Therefore, we designed Study 2 to address the question of causality. Specifically, we manipulated participants' sense of goal progress and examined whether it changed the other attributes of interest in our model. We also tested whether these attributes predicted future goal progress. Given that we did not expect our experimental manipulation to be particularly longlasting, we chose a much shorter time frame of a weekly goal of walking a certain number of steps.

Another aspect of Study 1 was that goal progress was measured only on a subjective level. As such, it could be influenced not only by actual progress but also by other factors. The 
fact that most of the variance in goal progress was explained at the goal level suggests that individual differences did not play a major role. Moreover, the vast literature on subjective perceptions of progress (e.g., self-efficacy, Bandura, 1997) suggests that they play a unique and independent role in goal pursuit. Still, it would be informative to supplement perceptions of progress with objective measures. The design of Study 2 allowed us to do so.

\section{Study 2}

This study aimed to provide a further test of reciprocal relationships between goal progress, importance, expectancy, and goal-related emotions. It took the form of a walking challenge in which participants aimed to walk $100 \mathrm{~K}$ steps in a week. We manipulated participants' sense of goal progress by providing them with positive or negative feedback at the beginning of the third day of the challenge. We then examined whether it changed the importance they attached to the goal of walking, expectancy of its attainment, satisfaction, and stress. We also tested whether these goal attributes predicted goal progress made on the same day and by the end of the challenge. We measured both subjective and objective goal progress (indexed as a number of steps). The study was preregistered and all study data, materials, and scripts are publicly available via osf.io.

\section{Method}

\section{Participants}

Participants were recruited via announcements posted on social media channels, the university participant pool, healthy lifestyle forums, and posters advertising the study with a QR code. All advertisements directed volunteers to the recruitment survey in which they could read about the study and, after consenting, sign up by providing an email address. We presented the study as research on the formation of healthy habits. Hence, individuals with all backgrounds 
(e.g., those who walk regularly and those who walk less often or not at all) were invited to participate. Participants could either win one of six vouchers to a store with sports goods worth 150 PLN ( $\sim 30)$, or, in the case of students enrolled in a participant pool, they could receive credit points.

Based on a priori power analysis, we aimed to recruit at least 200 participants. Such a sample size is required to detect a medium-to-small effect of $f=0.20$ in an ANOVA with two groups and a power of 0.80 (G*Power, Version 3.1; Faul et al., 2009). To budget for data losses and obtain greater power, we strived to recruit 300 participants but planned to analyze the data if we got at least 200 (see preregistration protocol).

In order to collect the minimal preregistered number of participants we needed to organize four separate data collections (February, April, May, and October 2022 ${ }^{6}$ ). In total, 442 participants took part in the challenge. In line with the preregistration protocol, we excluded those who did not last until the third day of challenge and did not complete the surveys on the third day $(n=167)$. Additionally, we excluded those who had guessed the study's purpose or our manipulation $(n=2)$. We also excluded participants who did not pass our comprehension check ( $n=38$, see Procedure). While this last exclusion was not foreseen in our preregistration we decided to do so because these participants were not able to correctly recall the content of the manipulation. Given that we did not have any other attention check that would allow us to filter out participants who were inattentive on the day of the manipulation, we decided to exclude them on the basis of this response ${ }^{7}$. Thus, the final sample comprised 235 participants (176 women, 50

\footnotetext{
${ }^{6}$ The effects of the manipulation did not differ between waves (see Supplementary Materials B).

${ }^{7}$ In the high-progress condition, we excluded three subjects who reported having made lower progress than other participants, six who reported the same progress, and five who did not know. In the low-progress condition, we excluded nine subjects who reported having made the same progress as other participants, six who reported higher progress, and nine who did not know.
} 
men, 2 other, 7 did not indicate their gender) aged between 18 to 55 years $(M=26.36, S D=$ $6.47,1$ participant who indicated their age was above 100 was excluded from the summary). The study was approved by the local Research Ethics Committee and with informed consent from all participants.

\section{Procedure}

The study lasted a week, starting on Monday and ending on Sunday. Throughout this time, participants monitored their steps with a phone app or a watch. Each day, they received a link to the survey in which they reported their daily progress, both subjective (self-report) and objective (the number of steps taken on that day). We sent the survey daily, typically around 5-6 p.m., and asked participants to fill it out before 10 a.m. the following day at the latest.

After two days of the challenge, on Wednesday morning, the experimental manipulation of subjective goal progress occurred. Specifically, participants were presented with the following introduction:

You are already on the third day of the challenge, and we have initial information on how other participants walk. One of the aims of this challenge is to find out how the social context influences goal attainment. Therefore, in this survey, we will present you with sample comments from other participants on how they feel about the challenge.

On the next screen we displayed four comments ostensibly coming from other participants. Two of them were positive, and two negative. The next screen contained the manipulation. Specifically, it presented the same comments on a visual summary showing where each of these individuals was compared to the rest of the group. This graph also displayed information about the participant's ostensible position relative to others (see Figure 3). Specifically, in the lowprogress condition, participants saw that their score was below $87 \%$ of other participants, 
meaning they had walked less than the vast majority of others. In the high-progress condition, participants saw that their score was above $87 \%$ of other participants, meaning they had walked more than the vast majority of others.

We checked participants' comprehension of this information by asking at the end of the survey whether their score was lower, the same, or higher than most participants (they could also answer "I do not know"). As mentioned earlier, only those who responded that their score was lower in the low-progress condition $(\mathrm{N}=109)$ and higher in the high-progress condition $(\mathrm{N}=$ 126) were included in the analyses.

\section{Figure 3}

Graphical Feedback Presented to Participants to Manipulate Goal Progress in Study 2

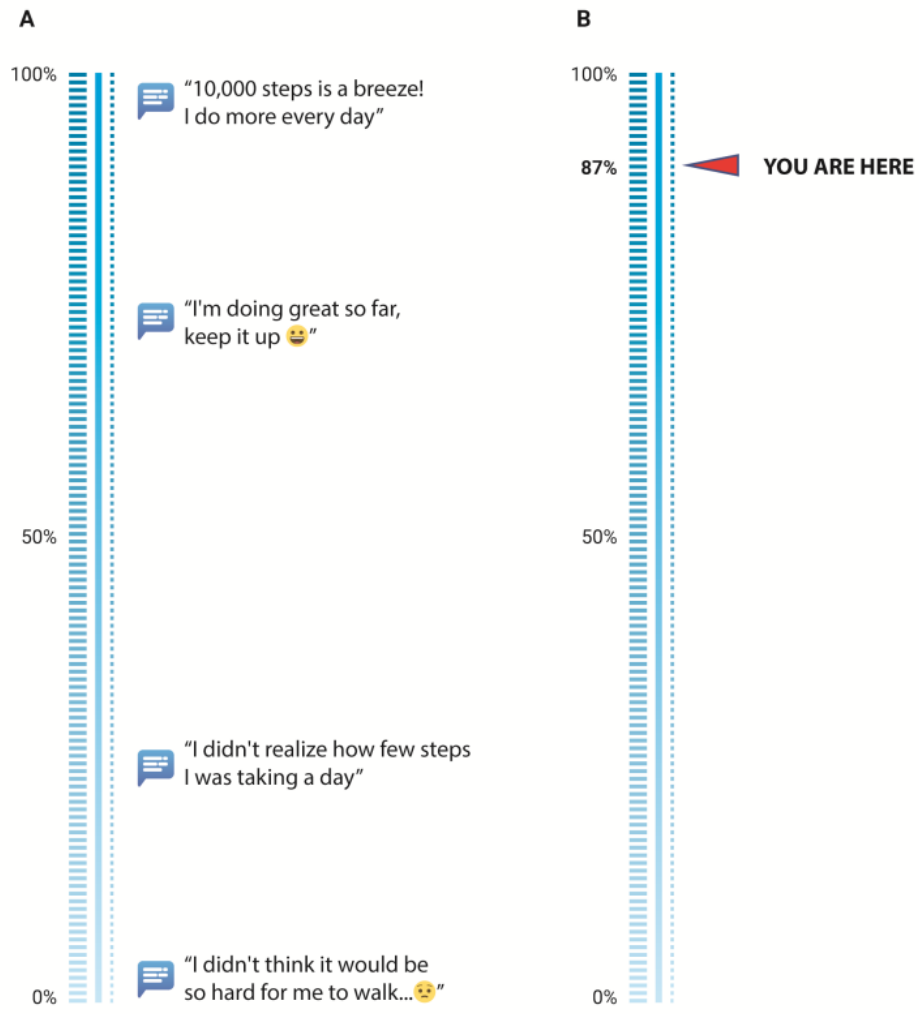

Note: All participants saw a visual summary of the progress in the challenge along four participants' comments (Panel A). Then, the second screen was presented. Participants in the high-progress condition saw a summary 
indicating that their score was higher than $87 \%$ of participants (Panel B). Participants in the low-progress condition saw a similar summary but their score was higher than only $13 \%$ of participants.

\section{Measures}

Every day participants reported subjective and objective progress using the following two questions.

\section{Subjective Goal Progress}

Subjective goal progress was measured with one item: "Please rate the progress you have made until now on the goal of walking 100K steps in a week." (1 - I have not started yet to 7 The goal has been completed).

\section{Objective Goal Progress}

Participants monitored their daily number of steps with mobile apps or watches. The most frequently used apps were Health (on iPhone, Samsung, or Huawei phones) and smartwatches/watches; people also used Google Fit, Garmin, MiFit/Zepp Life, and Pacer. Each day they entered the number of steps they walked on that day and uploaded a screenshot from their app or a photo of a watch displaying the number of steps.

After the manipulation received on Wednesday participants responded to a series of questions.

\section{Manipulation Checks}

To test whether the manipulation worked as intended, we measured participants' sense of progress. In addition to the item used to measure subjective progress described above we included one more item: "How close are you to attaining the goal of walking 100K steps in a week?" (1 - Very far to 7 - Very close).

\section{Goal Importance}


Two questions measured goal importance: "How important is the goal of walking $100 \mathrm{~K}$ steps in a week to you?" (1 - Not at all important to 7 - Very important), and "How important is the goal of walking $100 \mathrm{~K}$ steps in a week compared to your other goals?" (1- The least important of my goals to 7 - The most important of my goals). We averaged responses to the two items.

Additionally, we included four new items measuring extreme goal commitment modelled after Szumowska et al. (2023). Participants indicated to what extent they agreed with the following statements (from 1 - Definitely disagree to 7 - Definitely agree): 1) "The upcoming days will be dominated by this goal," 2) "I intend to devote most of my time and energy to this goal," 3) "I will stay committed to this goal even if it requires sacrifices to my other goals," 4) "I will devote myself to this goal to the extent that everything else will become insignificant." We averaged responses to these items to obtain another score of goal importance. In the preregistration, we planned to average all six items. However, averaging across all items would not allow us to compare the results of this study to Study 1 directly. Given that these four items measure intentions to invest effort in the future rather than goal importance directly, we decided to create two importance indices and analyze them separately.

\section{Goal Expectancy}

We measured goal expectancy with one item: "What is the likelihood of you attaining the goal of walking $100 \mathrm{~K}$ in w week?" (1 - Very unlikely to 7 - Certain).

\section{Goal-Related Satisfaction}

Participants rated their satisfaction using the item: "To what extent are you satisfied with the progress on the goal of walking 100K in a week?" from 1 (Very unsatisfied) to 7 (Very satisfied).

\section{Goal-Related Stress}


Participants rated their stress using the item: "To what extent does thinking of the progress on the goal of walking $100 \mathrm{~K}$ in a week stress you out?" from 1 (It does not stress me out at all) to 7 (It stresses me out a lot).

We measured these variables on Wednesday after the manipulation. Additionally, we measured them before the challenge (Day 0) and after the challenge ended (Day 7). We also included some exploratory variables (e.g., motivation to continue walking after the challenge ended and intentions to walk in the future). We present more information on these variables and their relationships to the focal variables in Supplementary Materials C.

\section{Results}

\section{Descriptive Statistics and Correlations}

Overall, out of the final sample, 211 participants participated in the entire challenge and completed the final survey; 43 participants have attained the goal and they walked $100 \mathrm{~K}$ steps, or more, in a week. Table 2 shows correlations between goal importance, goal expectancy, goalrelated satisfaction, goal-related stress, and goal progress (subjective and objective) on the crucial day of the study (Day 3) and progress at the end of the challenge (Day 7). Subjective and objective progress (the number of steps) across the seven days of the challenge are presented in Figure 4. 


\section{Table 2}

Means, Standard Deviations, And Correlations Between Variables Measured In Study 2

\begin{tabular}{|c|c|c|c|c|c|c|c|c|c|c|}
\hline Variable & $M$ & $S D$ & 1 & 2 & 3 & 4 & 6 & 6 & 7 & 8 \\
\hline $\begin{array}{l}\text { 1. Subjective Progress: } \\
\text { After Manipulation }\end{array}$ & 3.36 & 1.26 & & & & & & & & \\
\hline 2. Importance & 3.87 & 1.33 & $.30 * *$ & & & & & & & \\
\hline 3. Expectancy & 4.74 & 1.66 & $.57 * *$ & $.39 * *$ & & & & & & \\
\hline 4. Satisfaction & 4.00 & 1.83 & $.63 * *$ & $.26 * *$ & $.66 * *$ & & & & & \\
\hline 5. Stress & 2.70 & 1.59 & $-.15^{*}$ & $.27 * *$ & -.11 & $-.24 * *$ & & & & \\
\hline $\begin{array}{l}\text { 6. Subjective Progress: } \\
\text { End of Day } 3\end{array}$ & 3.65 & 1.26 & $.40 * *$ & $.21 * *$ & $.26 * *$ & $.31 * *$ & -.04 & & & \\
\hline $\begin{array}{l}\text { 7. Subjective Progress: } \\
\text { End of Day } 7\end{array}$ & 5.33 & 1.79 & $.19 * *$ & .09 & $.25 * *$ & $.14^{*}$ & -.08 & $.28 * *$ & & \\
\hline $\begin{array}{l}\text { 8. Objective Progress: } \\
\text { End of Day } 3^{\mathrm{a}}\end{array}$ & $11,892.08$ & $6,279.28$ & $.18 * *$ & .10 & $.18 * *$ & $.23 * *$ & -.05 & $.60 * *$ & $.26 * *$ & \\
\hline $\begin{array}{l}\text { 9. Objective Progress: } \\
\text { End of Day } 7 \text { (Total } \\
\text { steps no.) }^{\mathrm{a}}\end{array}$ & $79,195.84$ & $26,262.75$ & .12 & $.17 * *$ & $.17 * *$ & $.18^{* *}$ & .03 & $.39 * *$ & $.54 * *$ & $.52 * *$ \\
\hline
\end{tabular}

Note. $M$ and $S D$ represent mean and standard deviation, respectively.

${ }^{a}$ For the number of steps, we used robust statistical techniques. Specifically, we calculated percentage-bend correlations (Wilcox, 2017) using the WRS2 R package (Mair \& Wilcox, 2015). Percentage bend correlation, $\rho_{\mathrm{pb}}$, is a robust measure of the linear association between two random variables. When the underlying data are bivariate normal, $\rho_{\mathrm{pb}}$ gives essentially the same values as Pearson's $\rho$; however, $\rho_{\mathrm{pb}}$ is more robust to changes in the data and guards against the deleterious impact of outliers among the marginal distributions (Mair \& Wilcox, 2015).

$* p<.05$. ** $p<.01$. 


\section{Figure 4}

Pirateplots Presenting Participants' Subjective And Objective Progress

\section{Objective Progress: Number of Steps}

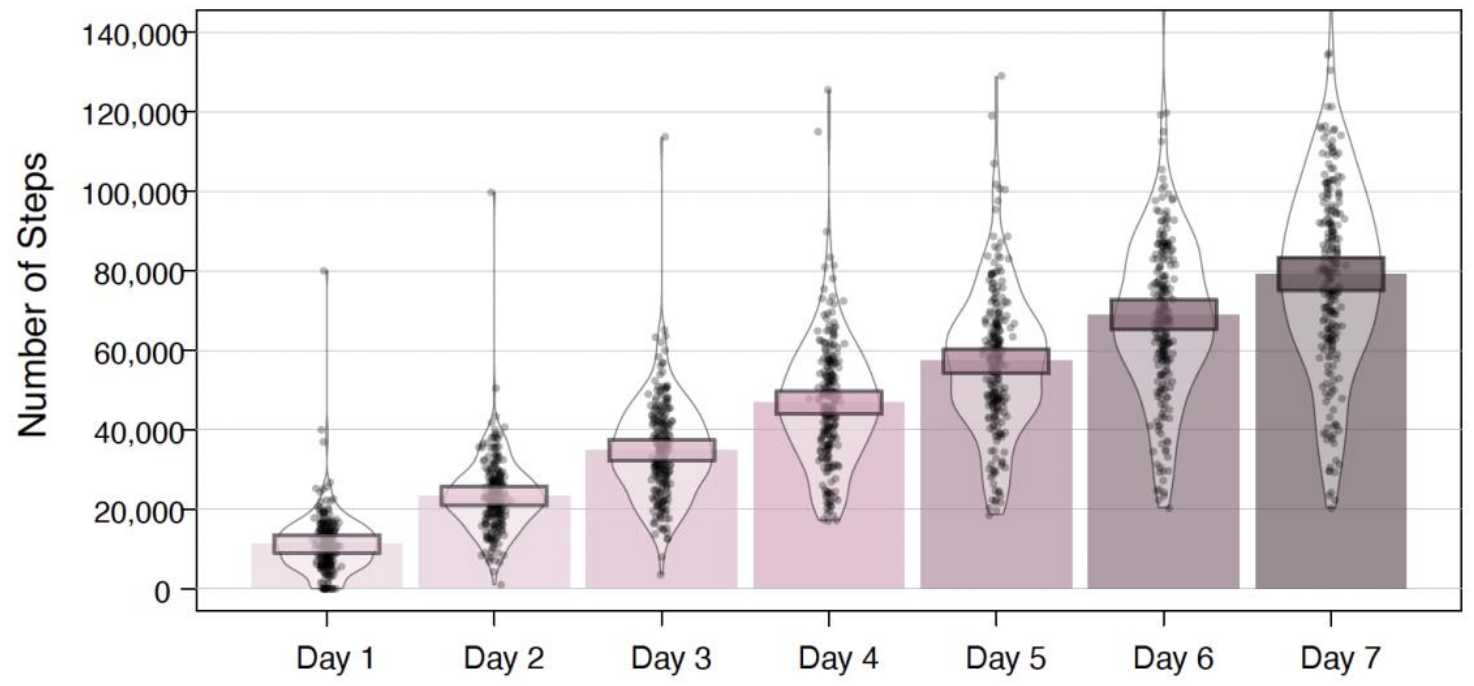

Subjective Progress: Participants' Ratings

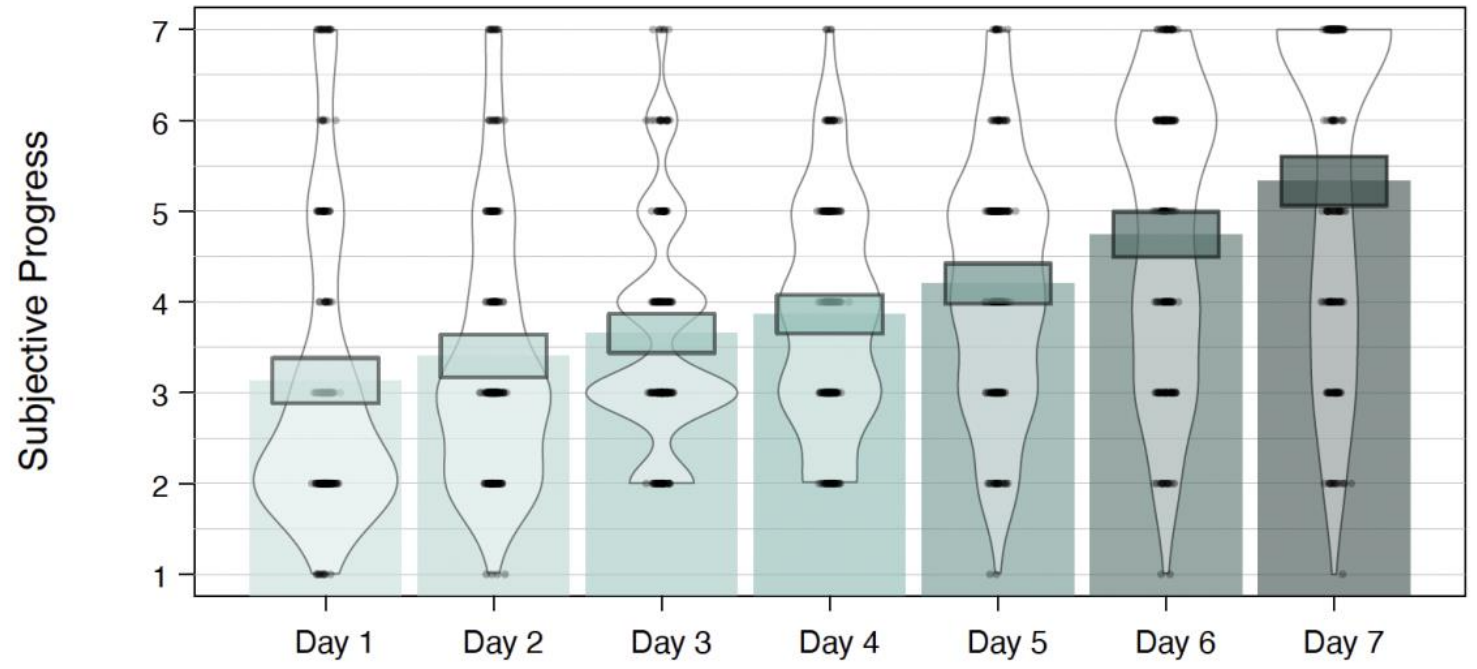

Note. We plotted pirateplots using the yarrr R package (Phillips, 2017). The points represent raw data (jittered horizontally), bars represent the means, beans - smoothed densities, and rectangles represent $95 \%$ confidence intervals. 


\section{Effects of Progress Manipulation}

To test the effects of our manipulation, we ran a set of one-way analyses of variance (ANOVAs) with condition as a between-subject factor. The manipulation was effective as it produced a significant difference on the both manipulation checks: subjective progress, $F(1,233)$ $=26.31, p<.001, \eta^{2}=.10$, and goal closeness, $F(1,233)=13.70, p<.001, \eta^{2}=.06$. The means for goal progress were $M=3.73(S D=1.35)$ and $M=2.93(S D=0.99)$ in the high-progress and low-progress condition, respectively. The same means for goal closeness were $M=3.41(S D=$ $1.55)$ and $\mathrm{M}=2.73(\mathrm{SD}=1.21)$.

Importantly, the manipulation also affected goal importance, expectancy, and satisfaction. These goal characteristics were significantly higher in the high- compared to the low-goal progress condition. The means for goal importance were $M=4.06(S D=1.31)$ and $M=$ $3.66(S D=1.32)$ in the high-progress and low-progress condition, respectively. The difference between conditions was significant, $F(1,233)=5.25, p=.023, \eta^{2}=0.02$. Also expectancy significantly differed between conditions, $F(1,233)=4.12, p=.044, \eta^{2}=0.02, M=4.94(S D=$ 1.64) vs. $M=4.50(S D=1.67)$. For satisfaction, we obtained an even stronger effect of goal progress manipulation: $M=4.35(S D=1.80)$ in the high-progress condition versus $M=3.60(S D$ $=1.79)$ in the low-progress condition, $F(1,233)=10.33, p=.001, \eta^{2}=0.04$. However, the means for stress, although in the right direction $(M=2.76, S D=1.61$ in the low-progress condition and $M=2.64, S D=1.58$ in the high-progress condition), did not significantly differ between conditions, $F(1,233)=0.34, p=.561, \eta^{2}=0.00$. Also, there was no significant difference on the new importance index, $F(1,231)=1.06, p=.304, \eta^{2}=0.00$, means equal to $M$ $=3.20(S D=1.22)$ and $M=3.03(S D=1.25)$ in the high- and low-progress conditions, respectively. We graphically summarized these results in Figure 5. 
Interestingly, when we look at the measured rather than manipulated progress (i.e., our manipulation check), it was related to all goal aspects, including stress (see Table 2). In line with expectations, the relationship between measured progress and stress was negative and the relationships between progress and other three variables were positive. The results thus show that goal progress affected importance, expectancy, and satisfaction, but not (or only indirectly) stress. Next, we test whether progress-induced changes in goal attributes predict future progress, that is, whether we can find support for a goal cycle hypothesis.

\section{Figure 5}

Pirateplots Presenting Goal Attributes in Both Conditions
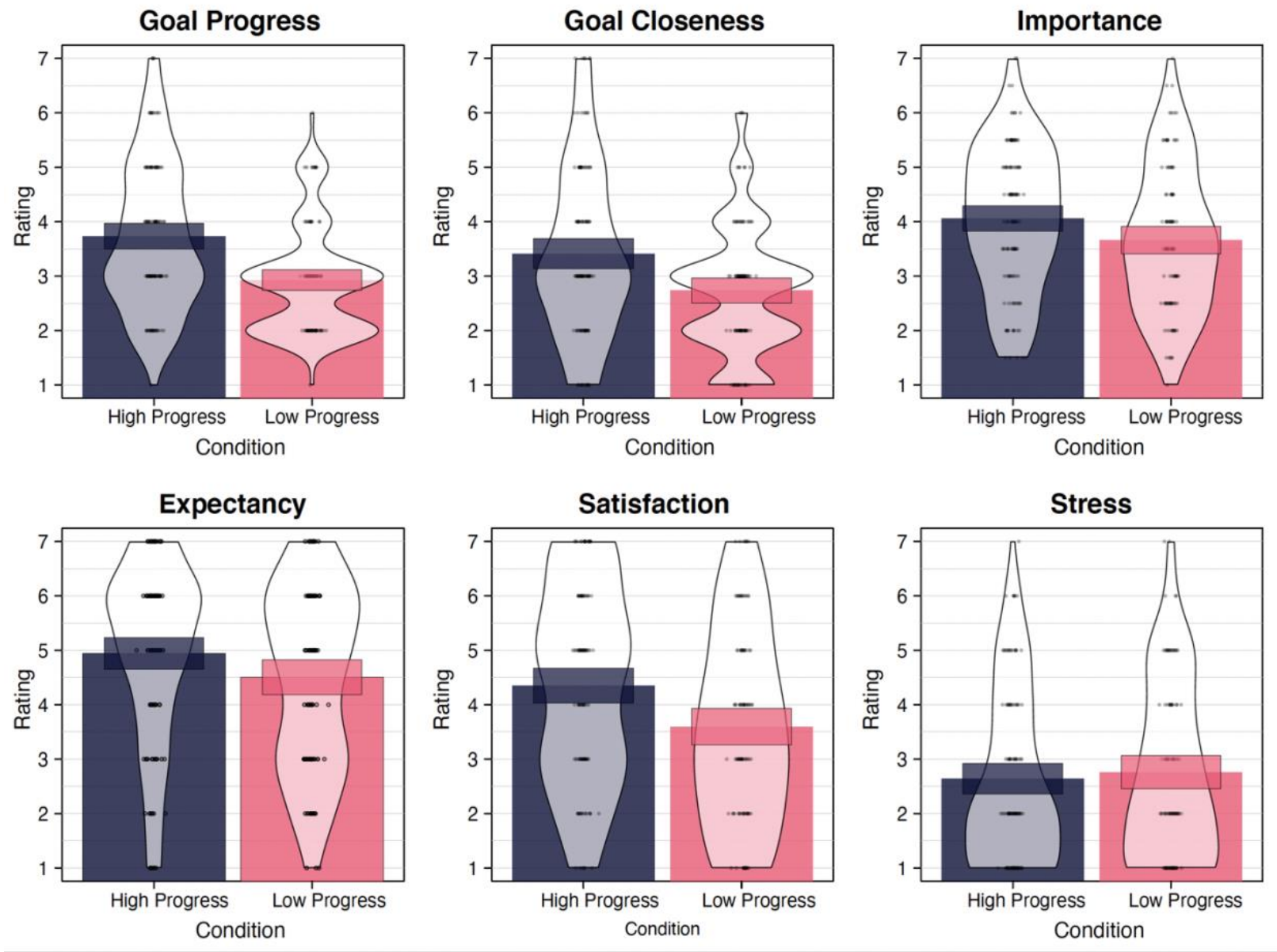
Note. We plotted pirateplots using the yarrr R package (Phillips, 2017). The points represent raw data (jittered horizontally), bars represent the means, beans - smoothed densities, and rectangles represent $95 \%$ confidence intervals.

\section{Goal Cycle}

In order to test our preregistered hypotheses regarding a goal cycle, we ran mediation models, in which experimental condition served as a main predictor $(0=$ low progress condition, $1=$ high progress condition), importance, expectancy, satisfaction, and stress were parallel mediators, and progress at the end of the day and progress at the end of the challenge were outcome variables. We ran the analyses with the lavaan R package (Rosseel, 2012).

As reported earlier, the condition exerted positive effects on importance, expectancy, and satisfaction measured after the manipulation. The effect on stress was not significant. The total effect of condition on progress at the end of the day was not significant $(T E=0.25, S E=0.16$, $95 \% C I[-0.07,0.57], p=.126)$. Out of the four parallel mediators, only satisfaction was positively related to progress reported at the end of the day $(B=0.16, S E=0.05,95 \% C I[0.05$, $0.26], p=.003)$. After including the mediators, the direct effect of condition remained not significant $(\mathrm{D} E=0.05, S E=0.16,95 \% C I[-0.26,0.36], p=.738)$. Only the indirect effect of the condition through satisfaction on progress measured at the end of the day was significant $(B=$ $0.13, S E=0.06,95 \% C I[0.05,0.29], p=.026)$. Other indirect effects were not significant $(p>=$ $.180)$.

We repeated the mediation model for the subjective progress at the end of the week. Only expectancy measured after the manipulation was positively related to progress reported at the end of the week $(B=0.27, S E=0.10,95 \% C I[0.08,0.46], p=.006)$. However, none of the indirect effects was significant $(p>.110)$. 
The results for objective progress (the number of steps) produced similar results. When we entered the number of steps on the day of the manipulation (Day 3) as a DV, condition as an IV, and the four parallel mediators, only satisfaction was positively related to progress $(B=0.18, S E$ $=0.09,95 \% C I[0.01,0.36], p=.038)$. However, neither the indirect effects nor the direct effect were significant. In these analyses, we also controlled for the mean number of steps on the previous days in case there were differences between conditions in how successful people were in their objective goal progress before the manipulation. We also analyzed the number of steps at the end of the challenge (i.e., the total number of steps) and found no significant effects of goal progress manipulated on Day 3 on the number of steps reached on Day 7 via the tested goal attributes (measured immediately after the manipulation). As exploratory analyses, we also looked into the relationships between goal attributes and progress, especially at the end of the challenge, and the intention to walk in the future. We present these analyses in Supplementary Material C.

\section{Additional Analyses: Subjective and Objective Progress}

One aspect of Study 2, not present in Study 1, is that we tracked both types of participants' progress, subjective and objective. Therefore, we could test the relationship between the two variables. These analyses demonstrated that whereas subjective and objective progress were, unsurprisingly, positively related, this relationship was not extremely strong (see Table 2).

Additional analysis of this relationship at the within-person level showed that this relationship was similarly and moderately strong. Specifically, this effect was equal to Est. = 0.55, $\mathrm{SE}=0.03, t=21.64, p<.001$ (lme4 R package, Bates et al., 2015, see Supplementary Materials $\mathrm{C}$ for the details of this analysis). At the same time, there was variability in how strongly these two variables were related: The model with a random (vs. fixed) slope was 
significantly better (deviance 3515.9 vs. 3551.1, $\chi^{2}(2)=35.16, p<.001$ ), suggesting that for some people their subjective sense of progress tracks their objective progress less closely than for others (see Figure 1S in Supplementary Materials C).

\section{Discussion}

Study 2 aimed to test the causal effects of goal progress on subsequent importance, expectancy, satisfaction, and stress. We were also interested in the cyclic effects of the progress manipulation on future progress via the change in the tested goal attributes. We found that goal progress manipulation significantly affected goal importance, expectancy, and satisfaction. All these effects were positive, meaning that the higher the progress, the greater the importance, expectancy, and satisfaction. These findings align with Study 1 and provide experimental evidence for the commitment hypothesis rather than the discrepancy hypothesis. These effects, however, were relatively small $\left(\eta^{2}\right.$ from 0.02 to 0.04 with the largest effect for satisfaction; at the same time, the effect on the manipulation check was equal to $\eta^{2}=0.10$ ).

However, the manipulation had no significant effects on stress (yet stress correlated negatively with the rated progress, see Table 2). The non-significant effect of manipulation on stress may stem from the timing of our manipulation. Feedback was provided to participants on Day 3 (after two days of the challenge), leaving still some time to make up for the lesser progress in the first few days. Likewise, there were no significant effects of the goal progress manipulation on the new index of goal importance. However, these items, unlike the importance items we used in both studies, pertain to the intent to invest effort in the upcoming days. Hence, they are more future (vs. present) oriented and capture intention, thus going beyond the sole importance aspect. It seems that the goal progress manipulation affected the importance, and not intention in our study. 
As for the cyclic effects of progress, or the indirect effects of progress on future progress via the tested goal attributes, we found only an indirect effect via satisfaction (when other three variables were controlled for), such that greater progress in the morning produced greater satisfaction, which in turn predicted greater progress at the end of the day. The results were similar for subjective and objective progress. As for progress at the end of the challenge, out of the four goal-related attributes measured on Day 3, only expectancy was a significant predictor the greater the expectancy after the manipulation, the greater the subjective progress and the more steps walked at the end of the challenge. However, there were no indirect effects of our manipulation.

This study also let us explore the relationship between subjective and objective progress. Unsurprisingly, these variables were positively, however, only moderately related. This suggests that they are, at least in part, independent. Additionally, we found variability in the strength (and the direction) of this relationship. This suggest that some people may monitor and update their subjective progress better than others. This is an interesting observation as it could suggest that they represent their progress differently (e.g., using shorter time intervals). Future research could investigate it in greater detail and the task that we used in our study could serve as an inspiration. Another interesting aspect of the subjective and objective progress concerns the rate of changes in both variables over time. A set of exploratory analyses with subsequent measurements nested within individuals showed steeper increase of objective progress over time than the subjective progress (see Supplementary Material C for more details). It seemed that when individuals have just started pursuing a goal, despite having accumulated only limited objective progress, they had already an elevated sense of progress. In contrast, when participants have made substantial progress and were approaching goal attainment, their sense of progress 
was not increasing by much. These results align with what Huang et al. (2012) found and it could serve a self-regulatory purpose by eliciting different strategies to mobilize effort at the beginning and toward the end of the goal-pursuit process.

\section{General Discussion}

Even though goal pursuit is often conceptualized and studied as a linear phenomenon, it is instead a dynamic, cyclical process that consists of feedback loops and reciprocal relationships between its crucial components. As individuals work towards their goals, they may make progress on some of their goals while experiencing setbacks on others, which can affect their emotional reactions and perception of these goals. These emotional responses and perceptions, in turn, impact the amount of effort they are willing to invest in the pursuit of their goals.

The goal of the present research was to examine the relationships between goal properties and goal progress using two different designs. Study 1 used a longitudinal design to gain insights into how these relationship unfold over time, particularly with respect to multiple personal goals. To test the effects of progress directly, in Study 2 we manipulated goal progress and measured its subsequent effects on other goal attributes. The discussion of the findings is divided into two sections. First, we examine the results concerning the path from goal importance and expectancy, via goal progress, to the subsequent changes in perceptions of importance and expectancy. Next, we analyze the second cyclical path, which begins with progress and moves through the emotions it elicits, predicting subsequent progress. A summary of the results along the hypothesized paths is presented in Table 3.

\section{Goal Cycle (1): From Goal Importance and Expectancy to Progress and Back}

While the positive effect of goal importance on goal progress is widely accepted in motivational psychology, there are few longitudinal studies that directly demonstrate these 
effects (but see e.g., Moeller et al., 2012; Beattie et al., 2015). Additionally, even when a longitudinal design is employed, it often concentrates on a single goal rather than multiple goals. In contrast, the current research (Study 1) examined the relationship between goal importance and goal progress across multiple goals that our participants were pursuing over the course of a semester. Interestingly, the relationship between goal importance and goal pursuit was not consistent over time. While goal importance at Wave 1 significantly predicted goal progress after two months, the same was not true for the subsequent two waves. Furthermore, in Study 2 we did not find the effect of goal importance measured after the manipulation on progress (subjective or objective) reported at a later time.

Notably, in our studies, the effects of importance were estimated after emotional reactions to progress had been controlled for. As such, our finding is in line with work by Woolley and Fishbach (2017), which demonstrated that the presence of immediate rewards (e.g., positive feelings associated with an activity) was a stronger predictor of goal persistence than the presence of delayed rewards (e.g., perception of the activity as important). After the former was taken into account the latter was often no longer significant. More generally, this raises a question regarding the more complex relationships that may exist among the variables we have included in our studies. While our research has taken the initial steps in describing the indirect effects that progress may exert on itself, we are still a long way from comprehending all the potential complexities involved in this process. For instance, it is possible that the effects of progress on satisfaction are mediated by the perceived importance of a goal. Due to the already complex nature of our model, we refrained from building sequential paths that would assume more causal directions than we had evidence for. Future research may investigate these paths directly. 
While these findings only partially align with the belief that a person's likelihood of achieving the goal is directly proportional to its importance (Gollwitzer, 1993), our main aim was to expand past models by exploring the reciprocal effect of goal progress on importance. With that regard, past theorizing could inspire two competing hypotheses. According to the commitment hypothesis, progress should increase goal importance, but according to the discrepancy hypothesis, the reverse should be true. Our results align with the former rather than the latter prediction. In Study 1, we found consistent positive relationships between perceptions of progress and goal importance. In Study 2, we also found that importance was significantly higher in the high (vs. low) goal progress condition. We did not find any evidence supporting the discrepancy hypothesis, according to which reduced distance between the current state and desired state should decrease goal importance. Overall, these results suggest that progress can be motivating through increased rather than decreased goal importance.

We also assessed the predictive power of goal expectancy, a second key variable expected to impact progress according to various models of motivation (Bandura, 1977; Beach \& Connelly, 2005; Eccles \& Wigfield, 2002; Locke \& Latham, 1990). According to these models, the belief that a goal can be achieved determines the effort invested in that goal leading to better results overall. The results of Study 1 provide support for these predictions. Expectancy of success was indeed a significant predictor of goal progress reported after two months, and this effect was consistent across all waves. In Study 2, the expectancy rated after the manipulation, while unrelated to progress at the end of the day, predicted subjective progress at the end of the challenge. The second part of this path was also supported as goal progress (measured in Study 1 and manipulated in Study 2) was in both studies positively related to expectancy. Overall, this is an additional piece of evidence to be considered in the discussion on the role of expectancy in 
goal pursuit (Bandura \& Locke, 2003; Sun et al., 2014).

\section{Goal Cycle (2): From Progress to Goal-related Emotions and Back}

Past research has also made a clear connection between goal progress and emotions. Emotions are often seen as indicators of how close or far people are from their desired outcomes. Our studies provide support for this notion. Study 1 found significant correlations between goal progress and feelings of stress and satisfaction across all three waves. Furthermore, Study 2 revealed that the perception of goal progress did indeed increase satisfaction, although it had no significant impact on stress, possibly for reasons mentioned earlier. Interestingly, stress and satisfaction were only weakly negatively correlated. It is in line with research on emotions (e.g., Watson et al., 1988) suggesting that positive and negative emotions form, to some extent, independent dimensions.

While the prediction regarding the positive effect of progress on satisfaction and negative effect on stress was not surprising, the direction of the impact of these emotional reactions on future progress was less clear. On the one hand, positive emotions may facilitate subsequent progress by inducing commitment to the goal. On the other hand, stress might also serve as a motivator by signaling the discrepancy and, thus, the need to invest more resources in the goal. Our results offer more support for the former rather than the latter hypothesis. First, across all waves of Study 1, goal-related satisfaction predicted greater progress reported after two months. Furthermore, in Study 2, satisfaction measured after the manipulation was positively linked to subjective (although not objective) progress reported at the end of the day. These results are again more in line with the commitment hypothesis suggesting that positive emotions evoked by progress may be more motivating than negative emotions in reaction to the lack of it.

In contrast, the results of stress were less consistent. Whereas in Study 1, stress 
experienced at the beginning of the semester did not predict progress two months later, it was positively related to goal progress by the end of the semester. The inconsistency could be a result of random variability present in our data. However, paralleling the effects of importance on progress, this might also suggest that the self-regulation process differs at various stages of goal pursuit (Vancouver et al., 2010), which would be in line with some theorizing on the changing role of affect in goal pursuit over time. According to this theorizing, the timing of the positive or negative feedback affects whether it makes the discrepancy or commitment framing more salient (Koo \& Fishbach, 2012). For instance, Louro, Pieters, and Zeelenberg (2008) showed that when the goal is remote, positive emotions motivate more effort, while negative emotions lead to goal disengagement. It happens because, at this stage, feedback predominantly conveys information about commitment. However, this pattern changes at later stages of goal pursuit, when feedback is interpreted in terms of discrepancy. Because of that positive emotions decrease effort, but negative emotions motivate greater persistence. In relation to our findings, this dynamic could mean that stress became a significant predictor only at later stages of goal pursuit, namely between Waves 2 and 3 in Study 1 and at the end of the weekly challenge in Study 2 (which is something that we did not measure). While an interesting possibility we have no way of testing it directly given that we cannot estimate the exact duration of goal pursuit in Study 1.

\section{Table 3}

Summary of Predictions and Results in Studies 1 and 2

\section{Hypotheses}

Results

\begin{tabular}{|l|l|c|c|}
\hline \multicolumn{2}{|c|}{ Study 1 } & Study 2 \\
\hline 1. Importance $\rightarrow$ Progress & Positive effect & Partially supported & Not supported \\
\hline 2. Expectancy $\rightarrow$ Progress & Positive effect & Supported & $\begin{array}{c}\text { Partially } \\
\text { supported }\end{array}$ \\
\hline 3. Progress $\rightarrow$ Expectancy & Positive effect & Supported & Supported \\
\hline
\end{tabular}




\begin{tabular}{|c|c|c|c|}
\hline \multirow{2}{*}{ 4. Progress $\rightarrow$ Importance } & $\begin{array}{l}\text { 4a. Discrepancy hypothesis: } \\
\text { negative effect }\end{array}$ & Not supported & Not supported \\
\hline & $\begin{array}{l}\text { 4b. Commitment hypothesis: } \\
\text { positive effect }\end{array}$ & Supported & Supported \\
\hline 5. Progress $\rightarrow$ Stress & Negative effect & Supported & Not supported \\
\hline 6. Progress $\rightarrow$ Satisfaction & Positive effect & Supported & Supported \\
\hline \multirow{2}{*}{ 7. Stress $\rightarrow$ Progress } & $\begin{array}{l}\text { 7a. Discrepancy hypothesis: } \\
\text { positive effect }\end{array}$ & Partially supported & Not supported \\
\hline & $\begin{array}{l}\text { 7b. Commitment hypothesis: } \\
\text { negative effect }\end{array}$ & Not supported & Not supported \\
\hline \multirow{2}{*}{ 8. Satisfaction $\rightarrow$ Progress } & $\begin{array}{l}\text { 8a. Discrepancy hypothesis: } \\
\text { negative effect }\end{array}$ & Not supported & Not supported \\
\hline & $\begin{array}{l}\text { 8b. Commitment hypothesis: } \\
\text { positive effect }\end{array}$ & Supported & Supported \\
\hline
\end{tabular}

\section{Limitations in the Study of Goal Cycle}

To examine the reciprocal mechanisms involved in goal pursuit, we used two different methodologies. Because of that, our studies differed in several important ways. Study 1 had a longitudinal design, in which we tracked the pursuit of multiple personal goals over several months. Study 2 used an experimental design in which we monitored the pursuit of a single goal of walking 100k steps over one week, which participants voluntarily adopted. The fact that our major conclusions were supported across both studies increases the generalizability of consistent findings. As discussed earlier, we found more support for the commitment hypothesis than the discrepancy hypothesis in both studies. At the same time, inconsistencies between the results may suggest possible directions for future explorations on goal pursuit and highlight methodological challenges in the study on goals and motivation and limitations of the present work.

The first major difference is that we obtained delayed effects of goal importance and expectancy on progress in Study 1, but we did not get these effects in Study 2. Precisely, goal importance and expectancy measured after the manipulation did not predict progress reported 
after even a short delay (on the same day or - with the exception of expectancy - at the end of the week). This discrepancy could be due to the difference in the nature of the goals pursued. In Study 1, participants were working towards personal goals they had likely set for themselves. In contrast, in Study 2, participants' task was to pursue a novel and, to some extent, an externally set goal. This difference may have resulted in less integration between ratings of goal importance and expectancy and other aspects of goal pursuit, leading to the absence of a delayed impact in Study 2. At this point we do not know what role the type of goals played in our studies but future research could directly address this issue.

Second, the short time interval (one week) could increase the motivational "noise" induced by other competing goals. Whereas people might find more opportunities to pursue their important goals against less important concerns over a longer period, this might be more difficult to achieve in a shorter time. The extent to which the type of goal (i.e., short-term goals with clear deadlines vs. long-term goals with more ambiguous endpoints) affects self-regulation would be an interesting direction for future studies. However, given that we only studied two distinct intervals, we do not know to what extent they generalize to other goal schedules.

Moreover, the fact that we measured progress daily in Study 2 could work as induction of a self-regulatory strategy, as research shows that monitoring progress is one of the most effective strategies (e.g., Harkin et al., 2016). It could also make it harder to abandon the goal, even when it was less personally important, when participants felt that they were constantly held accountable by researchers, who could constitute an external source of self-control and social motivation. This could explain the limited role that importance and expectancy played in predicting progress in that study. In short, future research could investigate the predictive role of goal properties over different periods and the role of assigned versus self-chosen goals. 
Another important observation we could make due to the design we adopted in Study 1 is related to the distinction between person-level and goal-level factors in goal pursuit. Specifically, the design and the analytical approach we utilized in Study 1 allowed us to estimate the amount of variance explained at the between-person and within-person (i.e., goal) levels. An important finding was that most of the variance was explained at the goal level rather than between individuals. Although the exact proportions differed between the goal attributes, this general observation was true for all of them. This finding has important implications for our understanding of the self-regulation process as it could shift the focus from individual differences in self-regulation to differences between specific goals. In the past, a number of personality-related constructs promoting goal attainment have been proposed such as self-control (Tangney et al., 2004), conscientiousness (John \& Srivastava, 1999), self-efficacy (Bandura, 1977), and grit (Duckworth et al., 2007). These findings led to a conclusion that some people are simply better self-regulators than others and that such predispositions account for differences in successful goal pursuit.

In contrast, our findings suggest that rather than some people being better at attaining their goals than others, it might be more useful to see some goals being more likely to be attained than others. Other studies have also found considerable variability within people and between goals (Holding et al., 2017; Milyavskaya et al., 2015; Werner et al., 2016). For example, Nurmi et al. (2009) found that appraisals of personal goals on various dimensions (such as importance, commitment, and meaning) vary predominantly within person, and only $5-24 \%$ of the variation in these appraisals can be attributed to individuals. A study on goal progress across time has found that approximately $80-95 \%$ of the variance in goal attainment was at the within-person level (Holding et al., 2017; Milyavskaya \& Inzlicht, 2017; Milyavskaya et al., 2015; Werner \& 
Milyavskaya, 2017; Werner et al., 2016). Our study adds to this growing body of literature by demonstrating a similar pattern for various goal attributes, including those not explored in previous studies. Taken together, these findings indicate that greater attention should be given to the goal-level in self-regulation research.

However, we do not suggest that investigations into individual differences be disregarded entirely. As previously mentioned, even though all participants in Study 2 pursued the same goal, we observed individual variability in how participants progressed toward their goal and how their perceptions of progress were related to the actual progress. Thus, comprehensively examining both the goal and person levels, along with their interrelationships, could lead to a deeper understanding of the self-regulation process. For instance, investigating how individual differences in optimism or self-esteem influence perceptions of goal importance and expectancy, and how they determine emotional reactions to goal progress or lack of it, could shed light on the mechanisms connecting both levels of analysis.

One additional limitation of the present research is that we concentrated on two general emotional reactions directly related to goal progress: satisfaction and stress. However, goals can evoke more specific emotions, each having different effects on motivation and subsequent progress. For instance, Higgins (1987) demonstrated that ideal goals bring disappointment, dissatisfaction, and sadness upon non-attainment and happiness and satisfaction upon attainment, whereas ought-to goals lead to fear, threat, and restlessness on non-attainment and to calmness and relaxation upon attainment (see also Higgins, Shah, \& Friedman, 1997; Idson, Liberman, \& Higgins, 2000). Similarly, research demonstrated different effects of stress depending on the interpretation of stress-inducing stimuli as challenging or threatening. This distinction could potentially help us understand the difference between quitting the goal (presumably at earlier 
stages of goal pursuit) vs. mobilizing more effort (possibly at later stages). Therefore, an interesting avenue for future research would be to test other, more specific emotions or framings related to goals and examine their role in determining progress on a given goal.

\section{Conclusion}

The results of two studies suggest that progress may fuel future progress through increased expectancy as well as via increased importance, although the former path is more reliable. A similar motivating role can be played by satisfaction derived from progressing on a given goal.

Overall, the results suggest that in order to better understand motivational dynamics research should devote more attention to a study of a full goal cycle at the goal rather than only at the individual level. 


\section{References}

Affleck, G., Tennen, H., Zautra, A., Urrows, S., Abeles, M., \& Karoly, P. (2001). Women's pursuit of personal goals in daily life with fibromyalgia: A value-expectancy analysis. Journal of Consulting and Clinical Psychology, 69(4), 587-596.

Ajzen, I., \& Kruglanski, A. W. (2019). Reasoned action in the service of goal pursuit. Psychological Review, 126(5), 774-786.

Atkinson, J. W., \& Birch, D. (1970). The dynamics of action. New York: Wiley. Bagozzi, R. P., Baumgartner, H. \& Pieters, R. (1998). Goal-directed emotions. Cognition \& Emotion, 12(1), 1-26.

Bandura, A. (1997). Self-efficacy: The exercise of control. New York, NY: W. H. Freeman.

Bates, D., Mächler, M., Bolker, B., \& Walker, S. (2015). Fitting Linear Mixed-Effects Models Using lme4. Journal of Statistical Software, 67(1), 1-48.

Bélanger, J. J., Kruglanski, A. W., Chen, X., Orehek, E. (2014). Bending perception to desire: Effects of task demands, motivation, and cognitive resources. Motivation \& Emotion, 38, 802-814.

Beach, L. R., \& Connolly, T. (2005). Foundations for organizational science.The psychology of decision making: People in organizations (2nd ed.). Sage Publications, Inc.

Beattie, S., Hardy, L., \& Woodman, T. (2015). A longitudinal examination of the interactive effects of goal importance and self-efficacy upon multiple life goal progress. Canadian Journal of Behavioural Science / Revue canadienne des sciences du comportement, 47(3), 201-206.

Bélanger, J. J., Schumpe, B. M., Lafrenière, M.-A. K., Giacomantonio, M., Brizi, A., Kruglanski, A. W. (2016). Beyond goal commitment: How expectancy shapes means evaluation. 
Motivation Science, 2, 67-84.

Boudreaux, M. J. \& Ozer, D.J. (2013). Goal conflict, goal striving, and psychological well-being. Motivation \& Emotion, 37, 433-443.

Carver, C. S., \& Scheier, M. F. (1998). On the self-regulation of behavior. New York, NY: Cambridge University Press.

Carver, C. S. (2004). Self-regulation of action and affect. In R. F. Baumeister \& K. D. Vohs (Eds.), Handbook of self-regulation: Research, theory, and applications (pp. 13-39). New York, NY: Guilford Press.

Carver, C. S. \& Scheier, M. F. (2009). Action, Affect, Multitasking, and Layers of Control. In J. P. Forgas, R. F. Baumeister, and D. M. Tice (Eds.), Psychology of Self-Regulation: Cognitive, Affective, and Motivational Processes (pp. 109-126). New York: Psychology Press.

Carver, C. S., \& Scheier, M. F. (2014). Dispositional optimism. Trends in Cognitive Sciences, 18(6), 293-299.

Chirkowska-Smolak, T. \& Grobelny, J. (2016). Konstrukcja i wstępna analiza psychometryczna Kwestionariusza Postrzeganego Stresu w Pracy (PSwP) [Construction and Initial Psychometric Analysis of the Perceived Stress Scale]. Czasopismo Psychologiczne [Psychological Journal], 22, 131-139.

Cohen, S., Kamarck, T., \& Mermelstein, R. (1983). A global measure of perceived stress. Journal of Health and Social Behavior, 24, 386-396.

Costa, P.T. Jr. \& McCrae, R.R. (1992). Revised NEO Personality Inventory (NEO-PI-R) and NEO Five-Factor Inventory (NEO-FFI) professional manual. Psychological Assessment Resources Inc, Odessa. 
Cryder, C. E., Loewenstein, G., \& Seltman, H. (2013). Goal gradient in helping behavior. Journal of Experimental Social Psychology, 49(6), 1078-1083.

Deci, E. L., \& Ryan, R. M. (1991). A motivational approach to self: Integration in personality. In R. A. Dienstbier (Ed.), Current theory and research in motivation, Vol. 38. Nebraska Symposium on Motivation, 1990: Perspectives on motivation (p. 237-288).

Diener, E., Emmons, R.A., Larson, R.J., \& Griffin, S. (1985). The Satisfaction With Life Scale. Journal of Personality Assessment, 49, 71-75.

Duckworth, A. L., Peterson, C., Matthews, M. D., \& Kelly, D. R. (2007). Grit: perseverance and passion for long-term goals. Journal of Personality and Social Psychology, 92(6), 10871101.

Eccles, J. S., \& Wigfield, A. (2002). Motivational beliefs, values, and goals. Annual Review of Psychology, 53(1), 109-132.

Faul, F., Erdfelder, E., Buchner, A., \& Lang, A.-G. (2009). Statistical power analyses using G* Power 3.1: Tests for correlation and regression analyses. Behavior Research Methods, 41, $1149-1160$.

Fishbach, A., \& Dhar, R. (2005). Goals as excuses or guides: The liberating effect of perceived goal progress on choice. Journal of Consumer Research, 32, 370-377.

Fishbach, A., Dhar, R., \& Zhang, Y. (2006). Subgoals as substitutes or complements: The role of goal accessibility. Journal of Personality and Social Psychology, 91, 232-242.

Fishbach, A., Eyal, T., \& Finkelstein, S. R. (2010). How positive and negative feedback motivate goal pursuit. Social and Personality Psychology Compass, 4(8), 517-530.

Fishbein, M., \& Ajzen, I. (2010). Predicting and changing behavior: The reasoned action approach. Psychology Press. 
Friedman, B. A., \& Mandel, R. G. (2009). The prediction of college student academic performance and retention: Application of expectancy and goal setting theories. Journal of College Student Retention: Research, Theory \& Practice, 11(2), 227-246.

Fox, J. \& Weisberg, S. (2019). An R Companion to Applied Regression, 3rd edition. Sage, Thousand Oaks CA. Förster, J., Higgins, E. T., \& Idson, L. C. (1998). Approach and avoidance strength during goal attainment: Regulatory focus and the "goal looms larger" effect. Journal of Personality and Social Psychology, 75(5), 1115-1131.

Gollwitzer, P.M., \& Bayer U. (1989). Deliberative versus implementational mindsets in the control of action. In S. Chaiken and Y. Trope (eds.), Dual-Process Theories in Social Psychology (pp. 403-22). Guilford.

Harkin, B., Webb, T. L., Chang, B. P., Prestwich, A., Conner, M., Kellar, I., ... \& Sheeran, P. (2016). Does monitoring goal progress promote goal attainment? A meta-analysis of the experimental evidence. Psychological Bulletin, 142(2), 198.

Higgins, E. T. (1987). Self-discrepancy: A theory relating self and affect. Psychological Review, 94, 319-340.

Higgins, E. T., Kruglanski, A. W., \& Pierro, A. (2003). Regulatory Mode: Locomotion and Assessment as Distinct Orientations. In M. P. Zanna (Ed.), Advances in experimental social psychology, Vol. 35 (p. 293-344). Elsevier Academic Press.

Higgins, E. T., Shah, J., \& Friedman, R. (1997). Emotional responses to goal attainment: Strength of regulatory focus as moderator. Journal of Personality and Social Psychology, $72(3), 515-525$.

Holding, A. C., Hope, N. H., Harvey, B., Marion Jetten, A. S., \& Koestner, R. (2017). Stuck in limbo: Motivational antecedents and consequences of experiencing action crises in 
personal goal pursuit. Journal of Personality, 85, 893-905.

Hollenbeck, J. R., \& Williams, C. R. (1987). Goal importance, self-focus, and the goal-setting process. Journal of Applied Psychology, 72, 204-211.

Huang, S. C., Zhang, Y., \& Broniarczyk, S. M. (2012). So near and yet so far: The mental representation of goal progress. Journal of Personality and Social Psychology, 103(2), 225.

Hull, C. L. (1932). The Goal-Gradient Hypothesis and Maze Learning. Psychological Review, $39(1), 25-43$.

Hull, C. L. (1934). The Rats' Speed of Locomotion Gradient in the Approach to Food. Journal of Comparative Psychology, 17(3), 393-422.

Idson, L. C., Liberman, N., \& Higgins, E. T. (2000). Distinguishing gains from nonlosses and losses from nongains: A regulatory focus perspective on hedonic intensity. Journal of Experimental Social Psychology, 36(3), 252-274.

Ingledew, D. K., Wray, J. L., Markland, D., \& Hardy, L. (2005). Work-related goal perceptions and affective well-being. Journal of Health Psychology, 10, 101-122

John, O. P., \& Srivastava, S. (1999). The Big Five trait taxonomy: History, measurement, and theoretical perspectives. Handbook of Personality: Theory and Research, 2(1999), 102138.

Juczyński, Z. (2001). Narzędzia do pomiaru w promocji i psychologii zdrowia [Measurement tools in health promotion and psychology]. Warszawa: PTP.

King, L. A., Richards, J. H., \& Stemmerich, E. (1998). Daily goals, life goals, and worst fears: Means, ends, and subjective well-being. Journal of Personality, 66, 713-744.

Kivetz, R., Urminsky, O., \& Zheng, Y. (2006). The goal-gradient hypothesis resurrected: Purchase acceleration, illusionary goal progress, and customer retention. Journal of 
Marketing Research, 43(1), 39-58.

Koo, M., \& Fishbach, A. (2012). The small-area hypothesis: Effects of progress monitoring on goal adherence. Journal of Consumer Research, 39(3), 493-509.

Kossowska, M., Szumowska, E., Szwed, P., Czernatowicz-Kukuczka, A., \& Kruglanski, A. W. (2020). Helping when the desire is low: Expectancy as a booster. Motivation \& Emotion, 44(6), 819-831.

Köpetz, C., Faber, T., Fishbach, A., \& Kruglanski, A. W. (2011). The multifinality constraints effect: How goal multiplicity narrows the means set to a focal end. Journal of Personality and Social Psychology, 100(5), 810-826.

Krys, S., Otte, K. P., \& Knipfer, K. (2020). Academic performance: A longitudinal study on the role of goal-directed rumination and psychological distress. Anxiety, stress, and coping, $33(5), 545-559$.

Kruglanski, A. W., Belanger, J. J., Chen, X., K.petz, C., Pierro, A., \& Mannetti, L. (2012). The energetics of motivated cognition: A force-field analysis. Psychological Review, 119, 120.

Kruglanski, A. W., Chernikova, M., Rosenzweig, E., Kopetz, C. (2014). On motivational readiness. Psychological Review, 121, 367-388.

Kruglanski, A. W., Szumowska, E., Kopetz, C. H., Vallerand, R. J., \& Pierro, A. (2022). On the psychology of extremism: How motivational imbalance breeds intemperance. Psychological Review, 128(2), 264-289.

Lawton, R., Conner, M., \& McEachan, R. (2009). Desire or reason: Predicting health behaviors from affective and cognitive attitudes. Health Psychology, 28(1), 56-65

Lewin, K., Dembo, T., Festinger, L., \& Sears, P. S. (1944). Level of aspiration. In J. McV. Hunt 
(Ed.), Personality and the behavior disorders (pp. 333-378). New York: Ronald.

Lench, H. C., \& Levine, L. J. (2008). Goals and responses to failure: Knowing when to hold them and when to fold them. Motivation and Emotion, 32(2), 127-

140. https://doi.org/10.1007/s11031-008-9085-1

Libeman, N., \& Forster, J. (2012). Goal gradients, expectancy, and value. In: Aarts, H., Elliot, A.L. (Eds.), Goal-Directed Behavior (pp. 151-173). Psychology Press, New York.

Locke, E. A., \& Latham, G. P. (1990). A theory of goal setting \& task performance. PrenticeHall, Inc.

Louro, M. J., Pieters, R., \& Zeelenberg, M. (2007). Dynamics of multiple-goal pursuit. Journal of personality and social psychology, 93(2), 174-193.

Maier, G. W., \& Brunstein, J. C. (2001). The role of personal work goals in newcomers' job satisfaction and organizational commitment: A longitudinal analysis. Journal of Applied Psychology, 86(5), 1034-1042.

Mischel, W. (1974). Processes in delay of gratification. In L. Berkowitz (Ed.), Advances in Experimental Social Psychology (pp. 249-292). New York: Academic Press.

Miller, G. A., Galanter, E., \& Pribram, K. H. (1960). Plans and the Structure of Behavior. Henry Holt.

Milyavskaya, M., \& Inzlicht, M. (2017). What's So Great About Self-Control? Examining the Importance of Effortful Self-Control and Temptation in Predicting Real-Life Depletion and Goal Attainment. Social Psychological and Personality Science, 8(6), 603-611.

Milyavskaya, M., Inzlicht, M., Hope, N., \& Koestner, R. (2015). Saying “no" to temptation: Want-to motivation improves self-regulation by reducing temptation rather than by increasing self-control. Journal of Personality and Social Psychology, 109, 677-693. 
Milyavskaya, M., \& Werner, K. M. (2018). Goal pursuit: Current state of affairs and directions for future research. Canadian Psychology/Psychologie Canadienne, 59(2), 163-175.

Mair, P., \& Wilcox, R. R. (2015). Robust statistical methods: The R package WRS2. https://CRAN.R-project.org/package=WRS2

Moeller, A. K.. Theiler, J. M. \& Wu, Ch. (2012). Goal Setting and Student Achievement: A Longitudinal Study. The Modern Language Journal, 96, 153-169.

Monzani, D., Steca, P., Greco, A., D’Addario, M., Pancani, L., \& Cappelletti, E. (2015). Effective pursuit of personal goals: The fostering effect of dispositional optimism on goal commitment and goal progress. Personality and Individual Differences, 82, 203-214.

Muthén, B. O., \& Muthen, L. (2018). Mplus (version 8.1)[Computer program]. The Authors.

Nurmi, J.-E., Salmela-Aro, K., \& Aunola, K. (2009). Personal goal appraisals vary across both individuals and goal contents. Personality and Individual Differences, 47, 498-503.

Nurmi, J. E., Salmela-Aro, K., \& Koivisto, P. (2002). Goal importance and related achievement beliefs and emotions during the transition from vocational school to work: Antecedents and consequences. Journal of Vocational Behavior, 60(2), 241-261.

Oatley, K., \& Johnson-Laird, P. N. (1987). Towards a cognitive theory of emotions. Cognition \& Emotion, 1, 29-50.

Phillips, N. (2017). Yarrr: A companion to the e-book “yarrr!: The pirate's guide to r". [Computer software manual]. Retrieved from https:/CRAN. R-project. org/package= yarrr (R package version 0.1.5).

Powers, W. T. (1973). Behavior: The control of perception. Oxford, England: Aldin.

Preacher, K. J., Zyphur, M. J., \& Zhang, Z. (2010). A general multilevel SEM framework for assessing multilevel mediation. Psychological Methods, 15, 209-233. 
Rand, K. L., Martin, A. D., \& Shea, A. M. (2011). Hope, but not optimism, predicts academic performance of law students beyond previous academic achievement. Journal of Research in Personality, 45(6), 683-686.

Read, D., Loewenstein, G., \& Kalyanaraman, S. (1999). Mixing virtue and vice: Combining the immediacy effect and the diversification heuristic. Journal of Behavioral Decision Making, 12(4), 257-273.

Rosseel, Y. (2012). lavaan: An R Package for Structural Equation Modeling. Journal of Statistical Software, 48(2), 1-36.

Ryan, R. M., \& Deci, E. L. (2000). Self-determination theory and the facilitation of intrinsic motivation, social development, and well-being. American Psychologist, 55, 68-78.

Segerstrom, S. C. (2007). Optimism and resources: Effects on each other and on health over 10 years. Journal of Research in Personality, 41(4), 772-786.

Schunk, D. H. (1995). Self-efficacy and education and instruction. In J. E. Maddux (Ed.), Selfefficacy, adaptation, and adjustment: Theory, research, and application (pp. 281-303). New York, NY: Plenum Press.

Selig, J. P., \& Preacher, K. J. (2008, June). Monte Carlo method for assessing mediation: An interactive tool for creating confidence intervals for indirect effects [Computer software]. Available from http://quantpsy.org/.

Shanahan, M. L., Fischer, I. C., \& Rand, K. L. (2020). Hope, optimism, and affect as predictors and consequences of expectancies: The potential moderating roles of perceived control and success. Journal of Research in Personality, 84, 103903.

Sheldon, K. M., Kasser, T., Smith, K., \& Share, T. (2002). Personal goals and psychological growth: testing an intervention to enhance goal attainment and personality integration. 
Journal of Personality, 70(1), 5-31.

Simon, H. A. (1967). Motivational and emotional controls of emotion. Psychological Review, 74, 29-39.

Solberg Nes, L., Evans, D. R., \& Segerstrom, S. C. (2009). Optimism and College Retention: Mediation by Motivation, Performance, and Adjustment 1. Journal of Applied Social Psychology, 39(8), 1887-1912.

Stein, N. L., Liwag, M. D., \& Wade, E. (1996). A goal-based approach to memory for emotional events: Implications for theories of understanding and socialization. In R.D. Kavanaugh, B. Zimmerberg, \& S. Fein (Eds.), Emotion: Interdisciplinary perspectives (pp. 91-118). Lawrence Erlbaum Associates Inc.

Szumowska, E., Kossowska, M., \& Roets, A. (2018). Motivation to comply with task rules and multitasking performance: The role of need for cognitive closure and goal importance. Motivation \& Emotion, 42(3), 360-376.

Szumowska, E., Molinario, E., Jaśko, K., Hudiyana, J., Fauko Firdiani, N., Penrod, J., Jaume, L.C., Leander, P., Kreienkamp, J., Agostini, M., \& Kruglanski, A. W. (2023). The Extreme Personality: Individual Differences in Proneness to Motivational Imbalance. Manuscript in preparation.

Tangney, J. P., Baumeister, R. F., \& Boone, A. L. (2004). High self-control predicts good adjustment, less pathology, better grades, and interpersonal success. Journal of Personality, $72,271-324$.

Vancouver, J. B., Weinhardt, J. M., \& Schmidt, A. M. (2010). A formal, computational theory of multiple-goal pursuit: Integrating goal-choice and goal-striving processes. Journal of Applied Psychology, 95(6), 985-1008. 
Vroom, V. H. (1964). Work and motivation. New York: Wiley.

Werner, K. M., \& Milyavskaya, M. (2017). We may not know what we want, but do we know what we need? Examining the ability to forecast need satisfaction in goal pursuit. Social Psychological and Personality Science.

Werner, K. M., Milyavskaya, M., Foxen-Craft, E., \& Koestner, R. (2016). Some goals just feel easier: Self-concordance leads to goal progress through subjective ease, not effort. Personality and Individual Differences, 96, 237-242.

Wiese, B. S., \& Freund, A. M. (2005). Goal progress makes one happy, or does it? Longitudinal findings from the work domain. Journal of Occupational and Organizational Psychology, 78(2), 287-304.

Wigfield, A., \& Eccles, J. S. (2000). Expectancy-value theory of achievement motivation. Contemporary educational psychology, 25(1), 68-81.

Wilcox, R. R. (2017). Introduction to robust estimation \& hypothesis testing (4th ed.). Elsevier.

Wright, R. A. (2008). Refining the prediction of effort: Brehm's distinction between potential motivation and motivation intensity. Social and Personality Psychology Compass, 2, 682701.

Woolley, K., \& Fishbach, A. (2017). Immediate Rewards Predict Adherence to Long-Term Goals. Personality and Social Psychology Bulletin, 43(2), 151-162.

Yukl, G., Kim, H., \& Chavez, C. (1999). Task importance, feasibility, and agent influence behaviour as determinants of target commitment. Journal of Applied Psychology, 84, 137143.

Zhang, Y., \& Fishbach, A. (2010). Counteracting obstacles with optimistic predictions. Journal of Experimental Psychology: General, 139(1), 16-31 